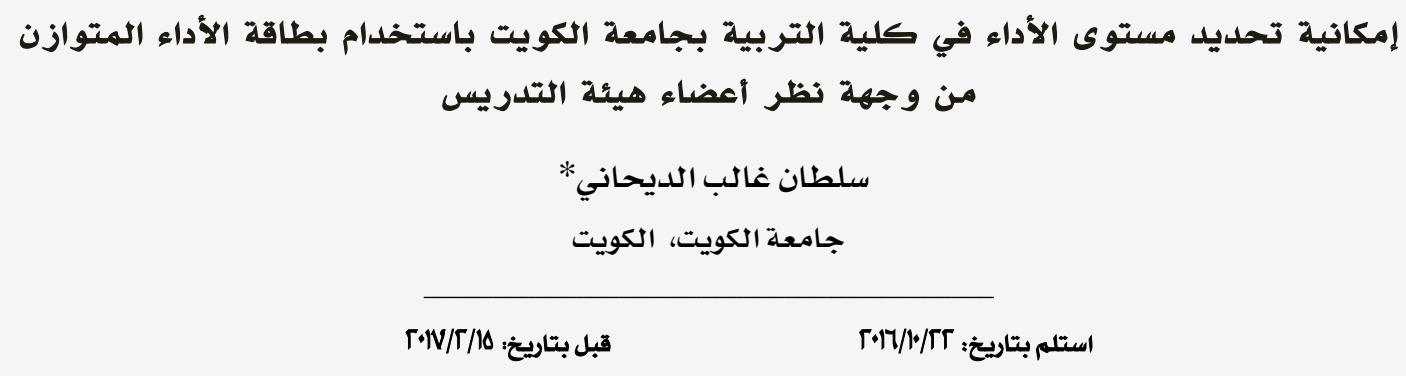

ملخص: هدفت الدراسة الحالية إلى التعرف على إمكانية تحديد مستوى الأداء ِّ كلية التربية بجامعة الكويت باستخدام بطاقة الأداء المتوازن من وجهة نظر أعضاء هيئة التدريس، واستخدم المنهج الوصفي من خلال أداة تم تطبيقها على (91) عضو هيئة تدريس

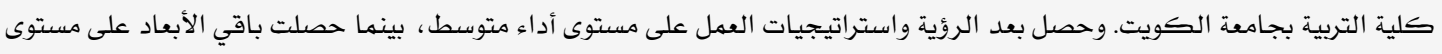
أداء ضعيف، ظهرت فروق ذات دلالة إحصائية لمتغير الدرجة العلمية لصالح الأسـاتذة وسنوات الخبرة لصالح اب فأعلى. واتضح أنه يهكن التتبؤ بهستوى الأداء المتعلق بالرؤية واستراتيجيات العمل وِّكلية التربية بناء على مستوى الأداء باستخدام بطاقة الأداء المتوازن، ولكن أثر محور العمليات الداخلية غير دال إحصائيا واقل يٌ التأثير على الرؤية واستراتيجيات العمل؛ بينها مجال الإدارة المالية كان الأعلى دلالة والأعلى تأثيرا. وقد انتهت الدراسـة إلى بعض التوصيات والمقترحات المهمة. كلمات مفتاحية: مستوى الأداء، بطاقة الأداء المتوازن، المنهج الوصفي، كلية التربية.

\title{
The Possibility of Determining the Level of Performance in the Faculty of Education at Kuwait University Using the 'Balanced Scorecard' from the Perspective of Faculty Members
}

Sultan G. Aldaihani*

Kuwait University, Kuwait

Abstract: This study aimed to identify the possibility of determining the level of performance in the Faculty of Education at Kuwait University using the 'Balanced Scorecard' from the point of view of faculty members. The study used the descriptive methodology through a tool which was applied to (98) faculty members in the College of Education at Kuwait University. The results showed that the 'vision and action strategies' have obtained an average performance, while the rest of the dimensions were of poor performance. There were statistically significant differences due to educational degree in favor of professors, and years of experience in favor of 21 years and above. The level of performance about the vision and action strategies can be predicted in the College of Education based on the level of performance using the 'Balanced Scorecard'. The effect of the domain 'the internal operations' was statistically insignificant and was less influential on the 'vision and action strategies'; while 'the financial management' was the highest in impact. In conclusion, the study proposed some important recommendations and suggestions.

Keywords: Performance level, balanced scorecard, descriptive method, college of education.

*Dr.aldihani@gmail.com 
الهستوى البيئة الخارجية و التي يتواجد فيها

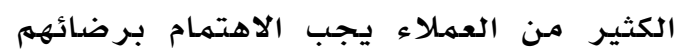

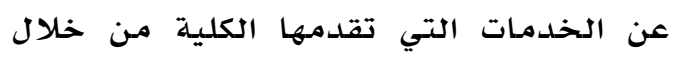

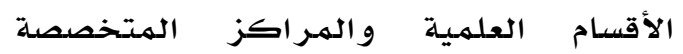

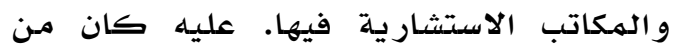
الههم الاعتماد على أحد أنظمـة الجودة، و التي

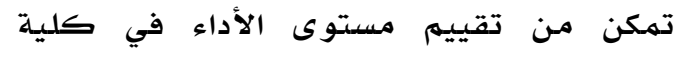
التربية بجامعة الكويت. وقدئ أوصت من الكثير

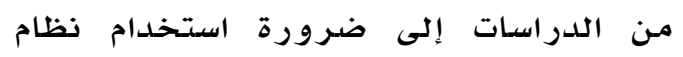
بطاقة الأداء المتوازن لتقييهم مستوى الأداء

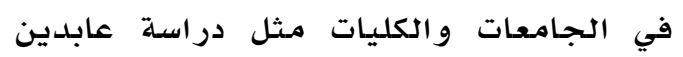

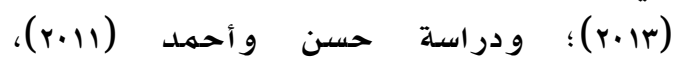
(Umashankar \& Dutta, 2007; وراستة

.Philbin, 2011)

و في دراسة هدفت إلى معرفة الكيفية التي يمكن بها تطبيق استراتيجية بطاقة الأداء

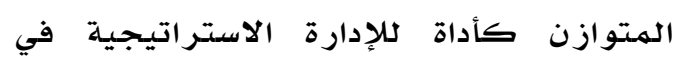

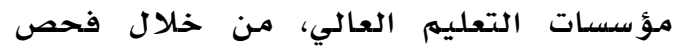

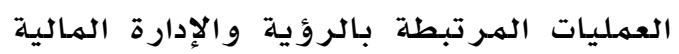

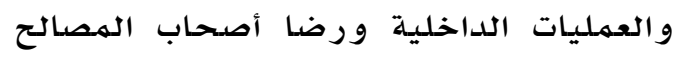

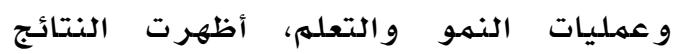

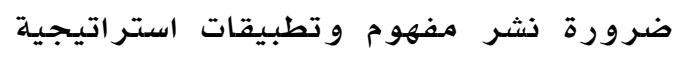

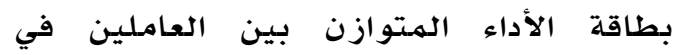

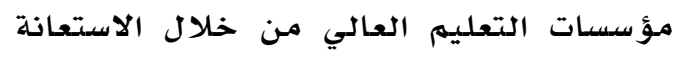
بجهود القيادات، إضافة إلى إمكانية و مناسبة التهاتية

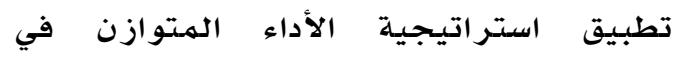
مؤسسات التعليه العالي ( Chen, Yang \& .(Shiau 2006

حاول أو ماشـانكر ودوتا (Dutta, 2007) الهتوازن وطرق تطبيق هذه الاستراتيجية في الجامعلة و الهعاهد الهندية. و جاءت نتائج

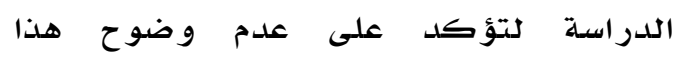
المفهوم في بيئات العمل بالجامعات و المعاهد الهندية، ويمثل تطبيق تلك الاستر اتيجية

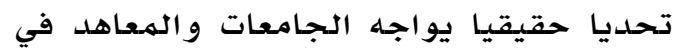

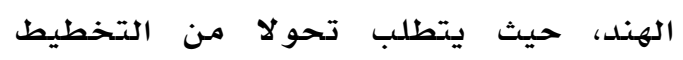
التقليدي إلى التخطيط الاستراتيجي التهبئي
يمثل العقد الأول من القرن الحهادي والعشرين فترة من الزمن لوحظ لون فيها التغييرات الكبيرة التي طر أت على مؤسسات

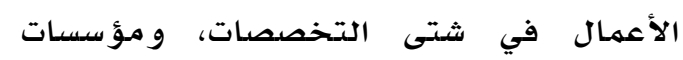

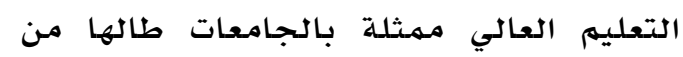

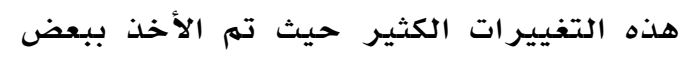

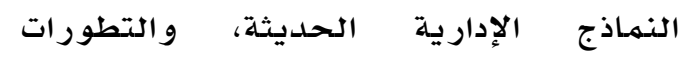

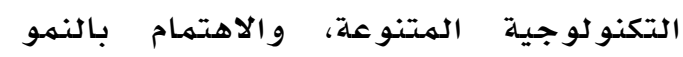

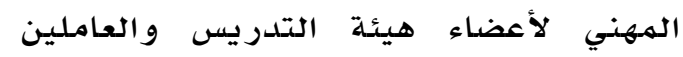

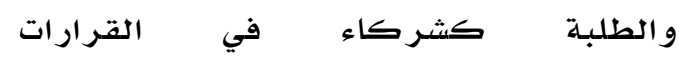

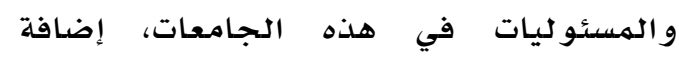
لوجود تنافس بين مقدمي الخدمات التعليمية

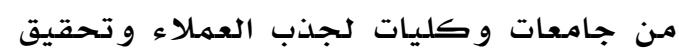

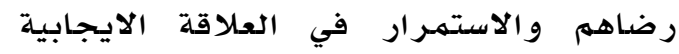

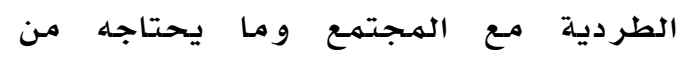

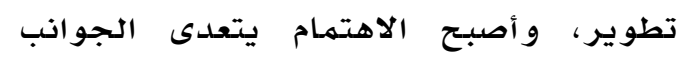

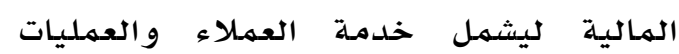

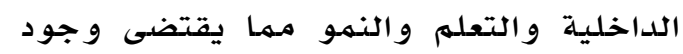
نظام يحقق التوازن بين هذه الأبعاد لتتمكن

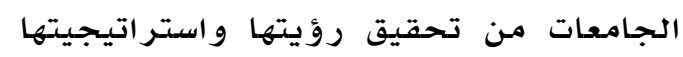
المعلنة والتي تم و ضعها من قبل شرعاء يعنيهم شأن تلك الجامعات و مستقبلها

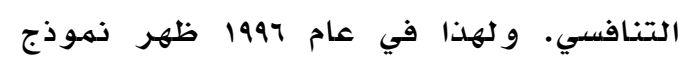
بطاقة الأداء المتوازن حيث يعتبر واحد ولد من الأن

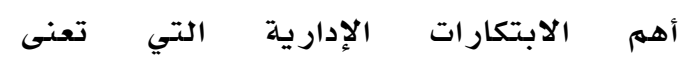

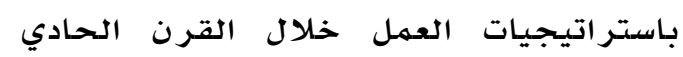

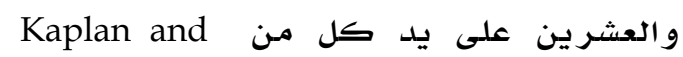
Norton

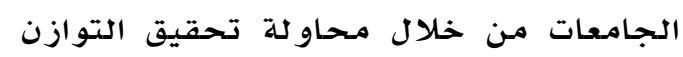

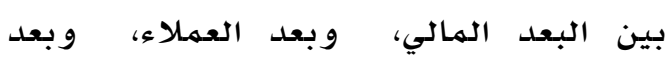

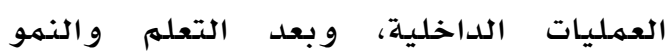
(Steele, 2001). حيث يتهم ربط هذاته الأبعاد

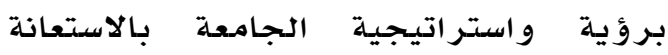
بعمليات قياس دوقيهة و ومحددة. و وكلية

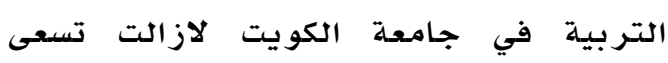

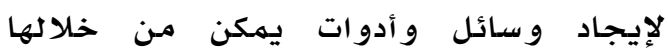

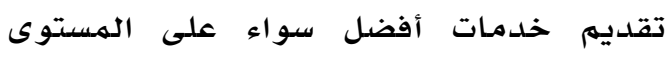

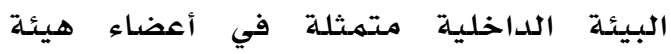

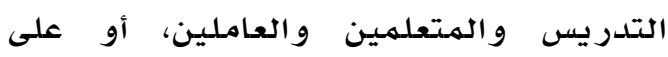


بطاقة الأداء المتوازن، و أشـارت النتائج إلى

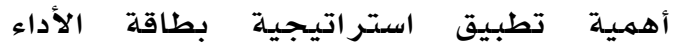

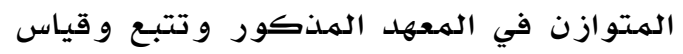

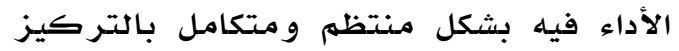

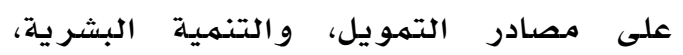
و الاستثمار في البحث العلهي، ووضع أدو أدلة

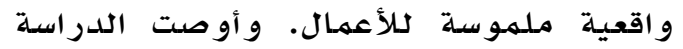

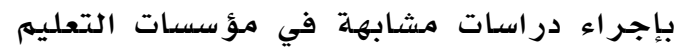

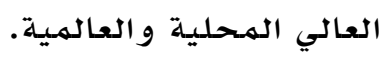

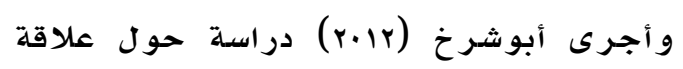

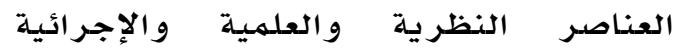
لاستراتيجية بطاقة الأداء المتوازن و إمكانية

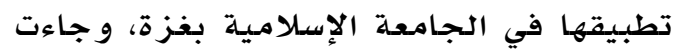

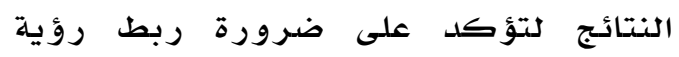

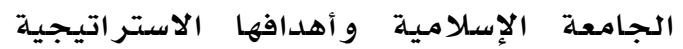

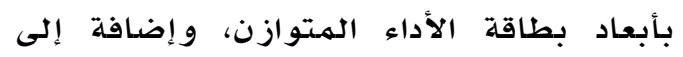

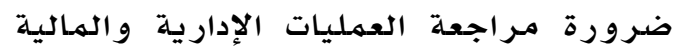
التي يتم من خلالها تحديد أسعار الساعات

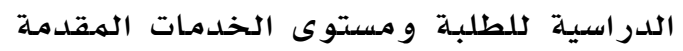

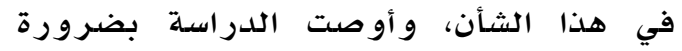

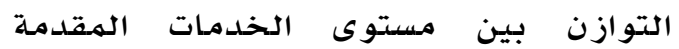

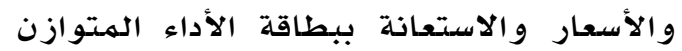
لتحقيق حالة التوازن المنشودة. وقام عابدين (r/r) بلدراسة حول إمكانية

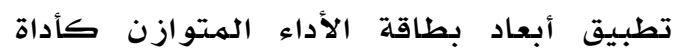

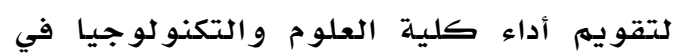
خان يونس، وأشارت النتائج إلى نجاح الكلية في تطبيق أبعاد بطاقة الأداء الهتوازن، واني

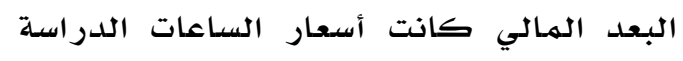

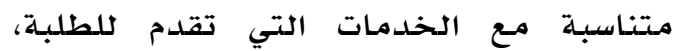

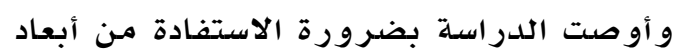
بطاقة الأداء المتوازن في زيادة الإيرادات المالية لتغطية نفقات الجامعة والهاء والعاملين

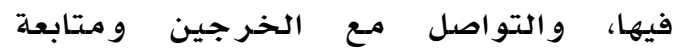
أوضاعهم عن كثب.

وبحث فالدير اما، وبورونيجو وبوردوي (Valderrama, Cornejo, \& Bordoy, 2013) العلاقة بين أبعاد بطاقة الأداء المتتوازن

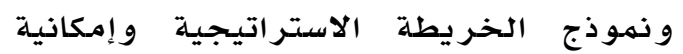

على مؤشر ات أداء و اقعية تعطي صورة شـاملـة

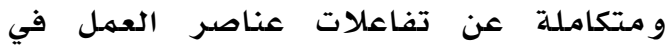
الجامعات والمعاهد الهندية، و وأوصت هذه

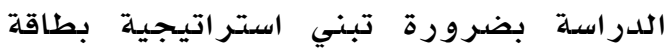

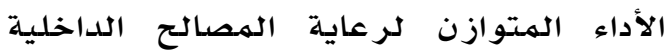
و الخار جية للجامعات و المعاهد الهندية. وقام كل من حسن و أحمد (r) (r) بدراسـة إمكانية تطبيق استراتيجية بطاقة الأداء

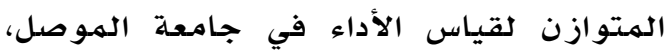

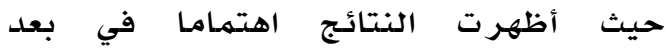

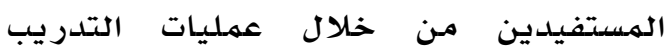
والاستشار ات الخارجية مقارنة بباقي الأبعاد،

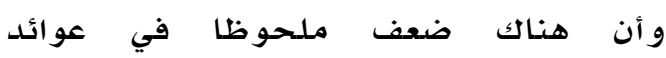

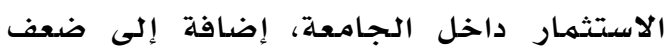

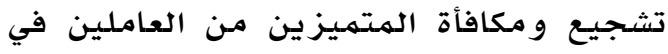

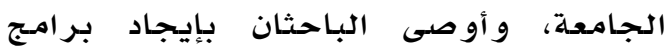

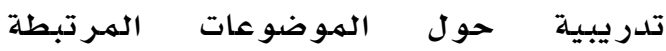

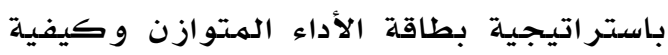

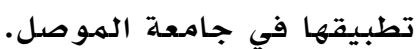

ومن خلال دراستها النظرية حاولت

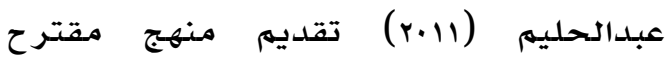
لتقييهم أداء الجامعات وتحسين جودة التعليه الجامعي من خلال الاستعانة بأبعاد بطاقة جودة بـاه

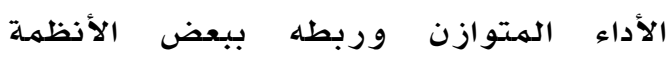
الهحاسبية التي يمكن تطبيقها في البيئة

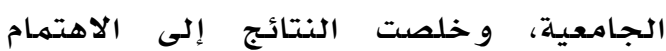

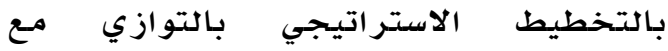

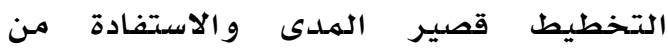

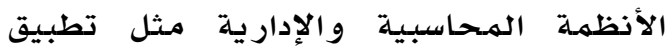

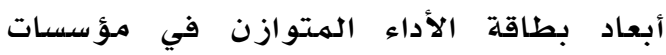

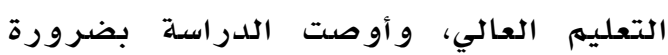

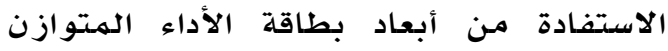

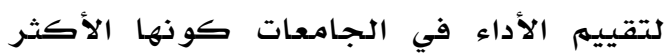

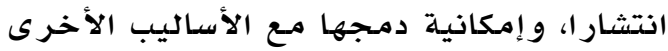
مثل أسلوب هوشين كونري لنشر السياسـة. و سدى فيلبين (Philbin, 2011) إلى تحديد كيفية تحسين الأداء في وسين وسين University Institute اعتماد نظام قياس الأداء المتكامل باستخدام 
و أعضداء هيئة التدريس على تطبيقات بطاقة

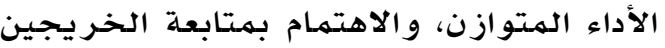
في بيئات العمل المـختلفة. مشكلة الدراسة مـن الواضـح تزايد الاهتمام بلدراسـة مؤشرات بطاقة الأداء المتوازن في الميدان التربوي و خصدوصـا الجامعات و مؤسسات التعليم

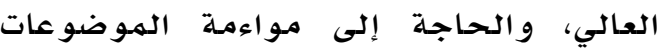

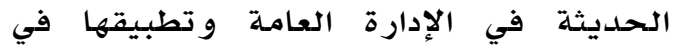

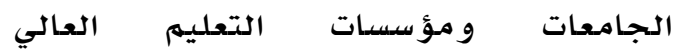
و يلاحظ عدم و جود مؤشرات (Hu, 2002) تقيس حاضر وموجودات مؤسسات التعليم

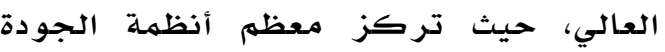
على قياس النتائج و المخرجات التي تعطي صورة عن الماضي دون النظر إلى حاضر

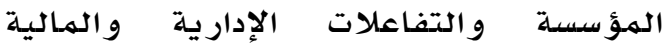

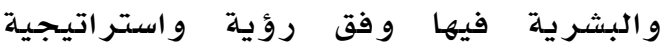
و اضحهة. و بالنظر إلى واقع كلية التربية في جامعة الكويت، حيث له تحصل كلية التربية على الاعتماد الأكاديمي حتى الوقت الحالي من مؤسسة ملنى مational Council for .Accreditation of Teacher Education و تم التحول إلى محاو لة تحقيق معايير الجودة مـن خلال الاستفادة مـن أنظمة الجولى الجودة التي تتناسب وطبيعـة العمل في المؤسسات

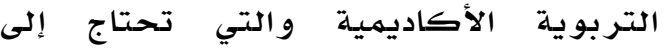
مؤشرات واضحة ودويقة اضهة حول حاضر الأداء في كلية التربية ونتائج الأعمال الماضية ودوالة

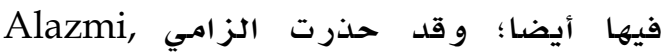
(2011) من أن كلية التربية بية بجامعة الكويت أخذت من الجودة الجوانب التوثيقية دون

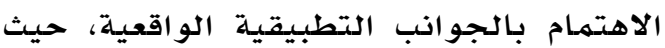
أظهرت نتائج الدراسـة أن هناك حاجـة مـاسـة

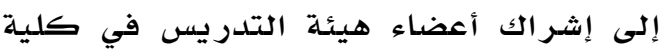

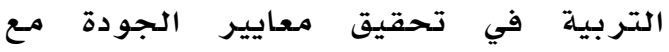

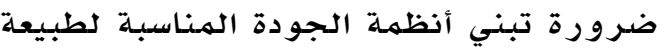
الكلية و العاملين فيها، و التي مـن خلادلها يمكن التهن تقييم الأعمال التي يقوم بها العاملون فيها.

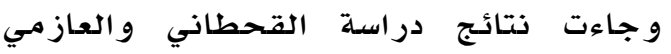

تطبيقها في جامعة University of Cádiz في اسبـانيا، وأظهرت النتائج علاقة مهمهة بين

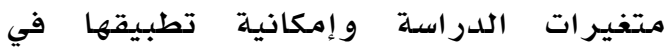
الجامعتة، و أوصى الباحثون بضرورة الاهتمام بالإبداع والابتكار لدى أعضاء هيئة التدريس

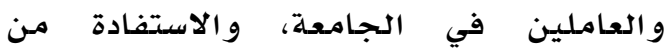
طاقاتهم و إمكانياتهم في الاستثمار الخارجي

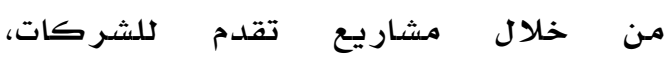

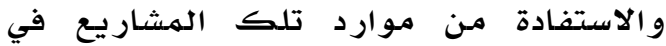

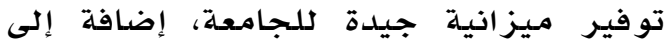
ضرورة الاهتمام برضا الطلبة عن الخدمات التي تقدمها الجامعلة، وأخيرا الاهتهام

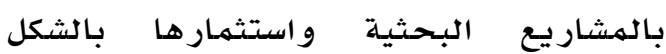
الصحيح لزيادة موارد الجامعة المالية.

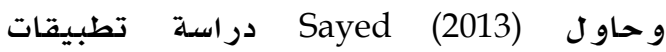

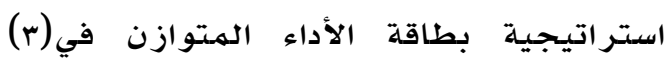

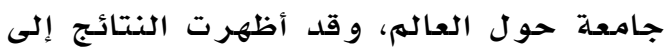

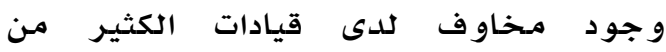

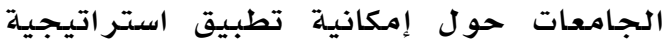

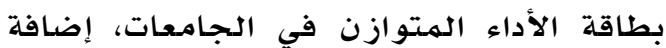

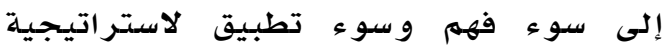

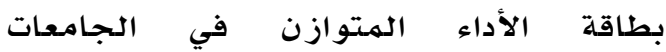
المشاركة في الدراسـة، وقد أوصى الهدواء الباحث بضرورة دراسـة إمكانية تطبيق استراتيجية بطاقة الأداء المتوازن في جامعات أخرىى على إسلى مستوى العاله، لنشر المعرفة حول مفهوم

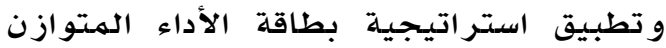

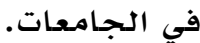

وقام الهنيني وزيادات (عابr) بدراسـة تهدف إلى تقييهم الجامعات الأردنية الرسمية من ولن خلال استخدام أبعاد بطاقة الأداء المتوازن. و وأغر اض الدراسـة تم تطبيق أداة على (vo) مشارك من الإداريين والأساتذة. وكاندانت أهم أهم النتائج تشير إلى أن الجامعات تفي بجمئع

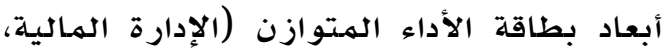

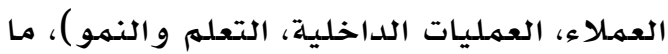

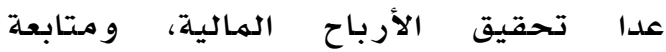

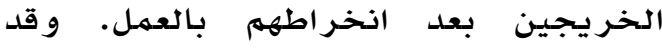

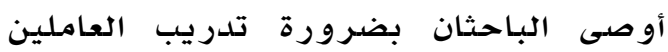


وجهة نظر أعضاء هيئة التدريس

تعزى لمتغيرات النوع، سنوات الخبهرة

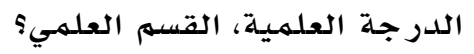

^. ما القدرة التتبؤية لبطاقة الأداء

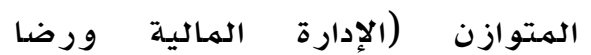

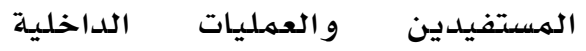

و التعلهم والنهمو) على تحقيق الهين الرؤية

و استر اتيجيات العمل في كلية واتهو التربية

بجامعة الكويتى

أهداف الدراسة

1. إمكانية تحديد مستوى الأداء في كلية

التربية بجامعة الكويت باستخدام

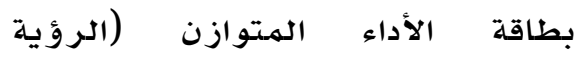

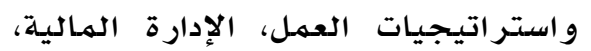

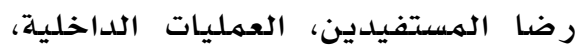

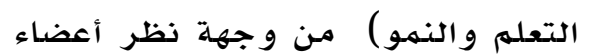
هيئة التدر يس.

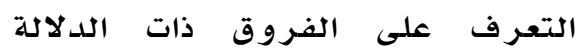

الإحصائية حول تقييهم مستوى الأداء

في كلية التربية بامعة الكويت

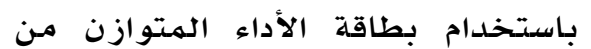

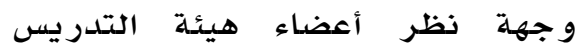

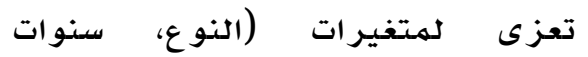

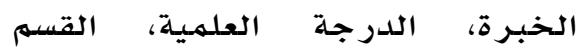

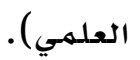

r. تتبع حجم أثر بطاقة الأداء المتوازن

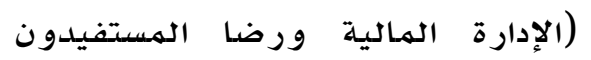

و العمليات الداخلية والادة التعلم والته والنهمو)

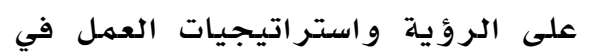

كلية التربية بجامعة الكويت.

أهمية الدراسة

تكمن أهمية الدراسلة الحالية في سعي قيادة كلية التربية بجامعة الكويت إلى تحقيق الهيه

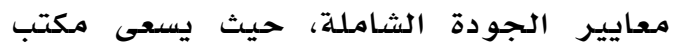

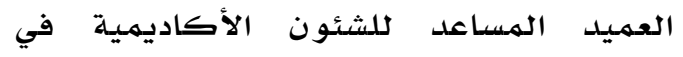

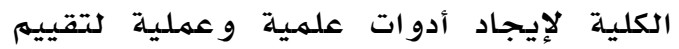
الأداء في الكلية، ونظرا لها يتميز بهاديه بهاد نظام

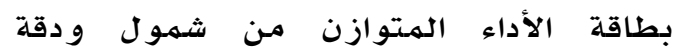

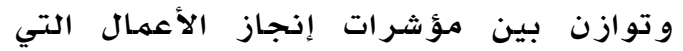

و المسحيلبي (r/r) لتؤكد على ضرورة التحسين الدائم وتطويرئ الأبر الأداء حتى تتمكن الكلية من تطبيق الاعتماد الأكاديمي، من خلال ايجاد وحدة للجودة الشاملة في الكلية تعهل على نشر ثقافة الجودة و وأنظهتها المختلفة. و وجاء تقرير قياس أداء جهامعة

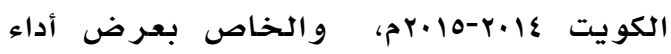
كل كلية على حلده، أن هناك حاجة للتوازن في الأداء والإنجاز بين الممارسات ولهات الأعمال في كلية التربية (الجاسم و والهطيري،

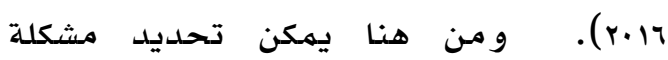

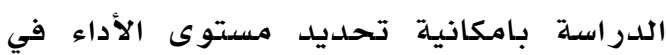
كلية التربية من خلال رصد أراء أعضاء هيئة التدر يس. أسئلة الدراسة

ا. ما مستوى الأداء في كلية التربية بجامعة الكويت باستخدام بطاقة الأداء المتوازن من وجهة نظر أعضاء هيئة التدر يس؟

r. ما مستوى الأداء مول الرؤية و استر اتيجيات العهل في كلية التربية من وجهة نظر أعضاء هيئة التدريس؟ r. ما إمكانية تحديد مستوى الأداء حول الإدارة المالية في كلية إمداليه التربية بية من من المداء و جهة نظر أعضاء هيئة التدريس؟ الهداره ع. ما إمكانية تحديد مستوى الأداء حول

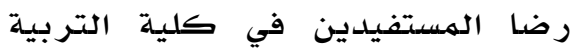
من وجهة نظر أعضاء هيئة التدريس؟ ه. ما إمكانية تحديد مستوى الأداء حول

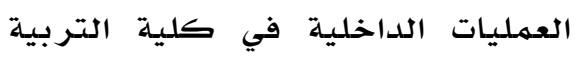
من وجهة نظر أعضاء هيئة التدريس؟ T. مـا إمكانية تحديد مستوى الأداء حول

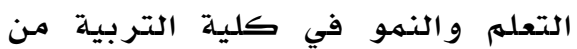
و جهة نظر أعضاء هيئة التدريس؟ V. هل هناك فروق ذات دلاكلة إحصدائية حول إمكانية تحدد مستوى الأداء في

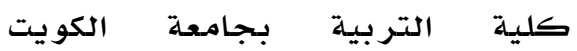
باستخدام بطاقة الأداء المتوازن من بن اعنه 
تقدمها كلية التربية انطلاقا من رؤيتها الاستر اتيجية التي تسعى مـن خلالها لتحقيق

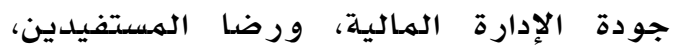
و العمليات الداخلية، و والتعلهم و النهمو، و التي التهاه تسهم في إعداد معلمين على مستوى عال من الكفاءة و التمكن.

تقييم الأداء: ذكر الحجار (ع..r) أن تقييم

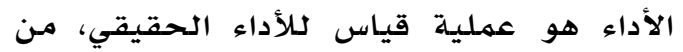

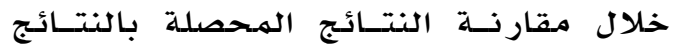
المنشودة، حتى تتكون صورة حيسة لما حدث الداث

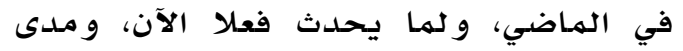

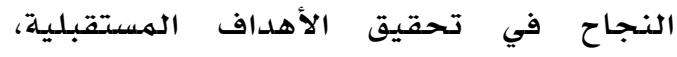

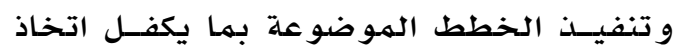

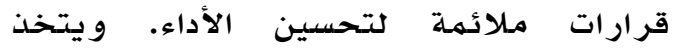
الباحث من المصطلح أعلاه تعريفا إجرائيا للدر اسـة. و قصدت به أبوشعرة (r..v) "التوصل إلى (الى

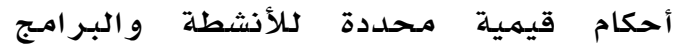
الجامعية من خلال استخدام بعض الهقاييس

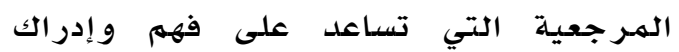
العلاقة المهختلفة بين مختلف العناصر الخاصة بالتقويه، وأنه يستند إلى معايير محددة تخضع لها جميع مكونات العمل في الكلية التي يمكن قياسها، بحيث يمكن من خلال هذه المعايير الحكم على أداء الكلية

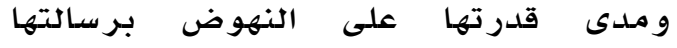

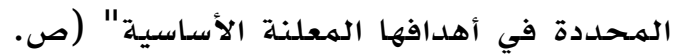

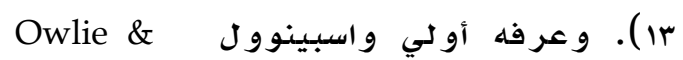
(Aspinwall, 1996)

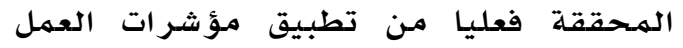

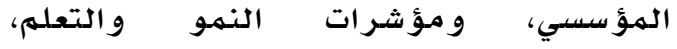

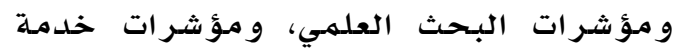
المجتهـع من قبل مؤسسـات التعليهم العالي.

\section{أهمية تقييم الأداء في الكليات}

تكمن أهمية تقييم أداء الجامعات والكليات

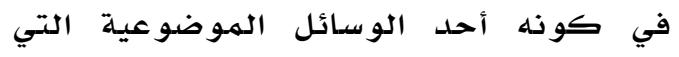
تحقق مبدأ الشفافية ونش ونشر المعلومات و البيانات للمستفيد من خلال الكشف عن

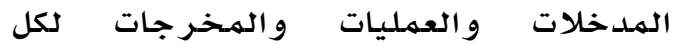

تتناسب مع طبيعة كلية التربية وخططها التطويرية وحاجاتها الواقعية. من هنا حاول الباحث إجراء هذه الدراسلة إمكانية تحلديد الهوايل

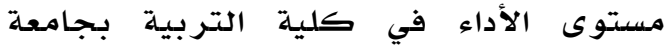

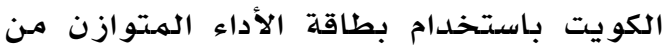
و جهة نظر أعضاء هيئة التدريس.

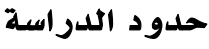

الحدود المـوضوعية: إمكانية تحديد مستوى الأداء في كلية التربية

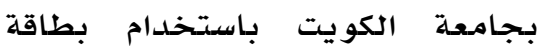

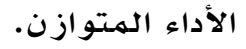

الحدود البشرية: أعضاء هيئة

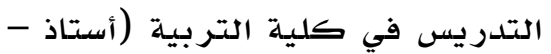

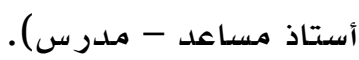

الحدود المكانية: كلية التربية -

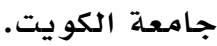

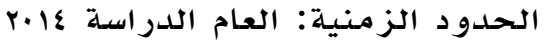
.r. 10-

\section{مصطلحات الدراسة}

الأداء: لغة، عرفه الرازي (1994) أنه الدليل

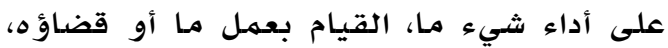

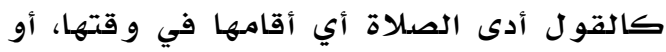

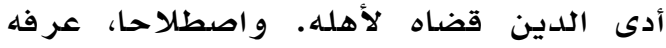

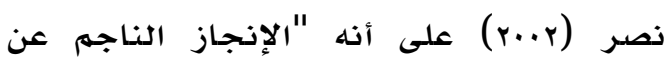

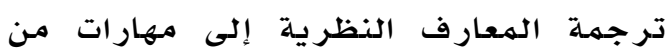

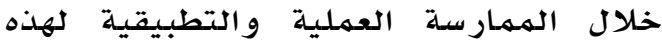

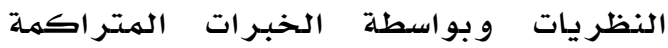

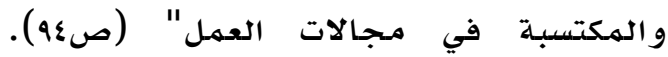
ويعرف الأداء بأنه القدرة على قياس نتائج الأعمال التي و جدت بسبب التفاعل الايجابي

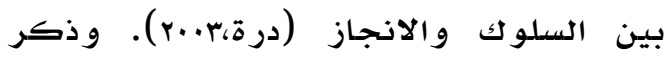

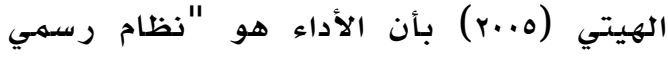
لقياس وتقييم التأثير في خصائص الفرد

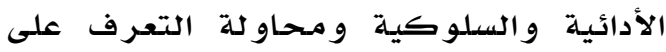

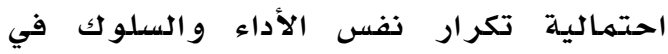
المستقبل لإفادة الفرد و المنظمة و المـجتمـع (ص199). و يعرف الباحث الأداء إجرائيا بأنه جميع الأعمال والأنشطة والخدمات التيات التئي 
و الفعاليات (7) بر امـج الاعتماد والجودة الداخلية والمعانيات الخارجية.

مفهوم بطاقة الأداء المتوازن: فكرة عمل بطاقة الأداء المتوازن تتمهور مولمول حول منهج

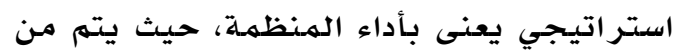

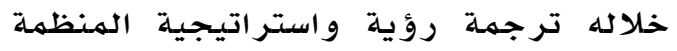
إلى واقع تنفيذي يمكن قياسـ و ومتابعته (Afriliana \& Goel, 2014)

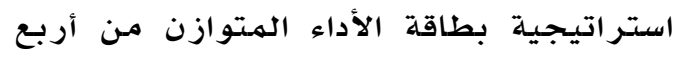

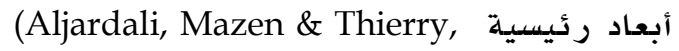

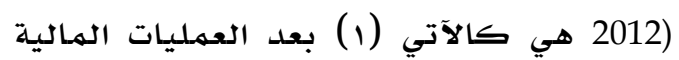
(الإدارة الهالية)، (r) بعد العميل (المستفيد)،

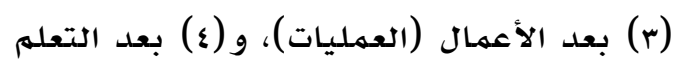
و النهمو.

تاريخ بطاقة الأداء المتوازن: الههرت استراتيجية بطاقة الأداء المتوازن في بلداء بلداية التسعينات من القرن الماضي على يد سيمون آحئه و آخرون، حيث كان أول ظهور لبطاقة الأداء المتوازن في عام Norton and Robert Kaplan بعنوان "بطاقة قياس الأداء الهتوازن لقياس دوافع العمل" في أحدى مجلى فيلات الأعمال

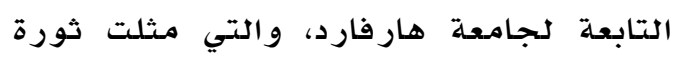

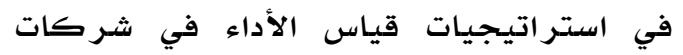
الأعمال (Umashankar \& Dutta, 2007). فلسفة بطاقة الأداء المتوازن: و تقوم فلسفة بطاقة الأداء المتوازن التي سـاد استخدامها

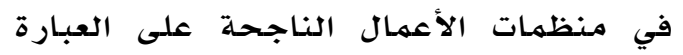
القائلة "إذا لهم يمكنك القيـاس الاس لا يمكنكال

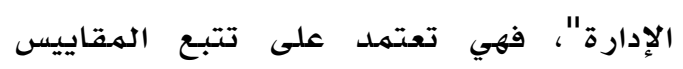

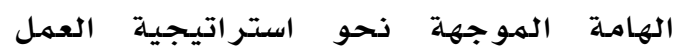

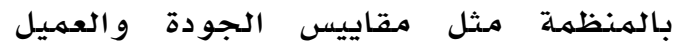
و الابتكار و حصدة السوق التي يمكن أن تعكس

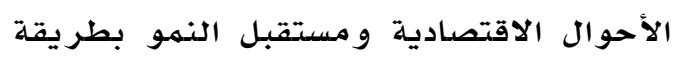

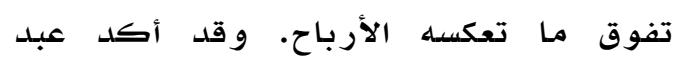

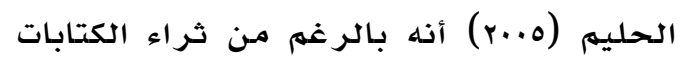

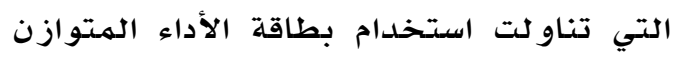

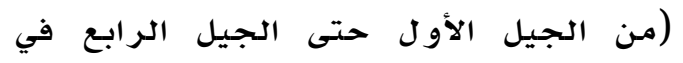
منظمات الأعمال )، نجد الجد أن البحوث الجيل التي التع
الأعمال التي يتهم انجازها في الجامعة

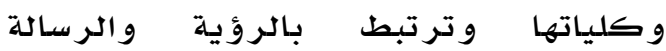

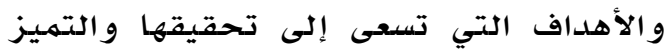

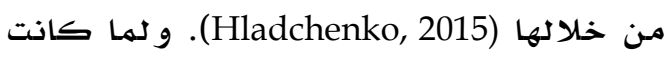
إحلدى أدوات قياس تقدم الجامعات تتمثل في

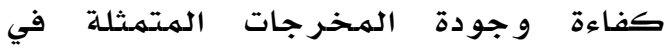
خريجي هذه الكليات والمستوى الأكاديهي

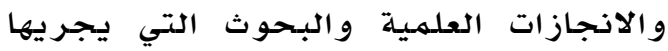

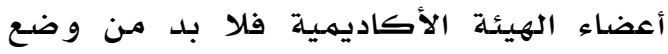

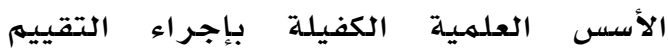
المطلوب والخروج بنتائج يمكن الاطمئنان

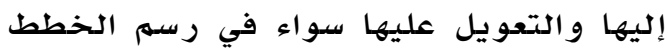
أو التخاذ القرارات. ومن الأهداف الهمهمهة

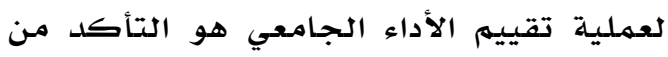
التحسين المستهمر لجودة الأعمال الهختلفة هولة الهاء التي تقدمها الجامعة والتي من خلالدها تؤثر

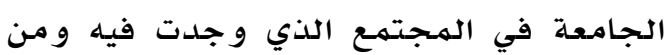

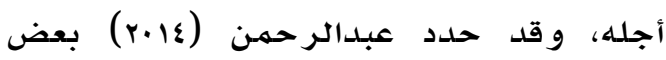

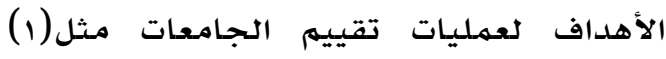
تحسين مستوى أداء الجامعات والكليات التابعة لها اعتمادا على المعلومات الناتجلة الجهاء

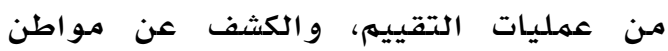
القوة و الضعف واستثمهار ها بشكل الأمثل، (r) تحقيق متطلبات واحتياجات الجهات ذات ذات الجهات

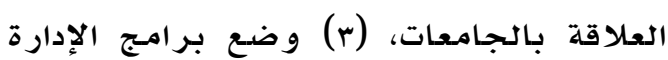

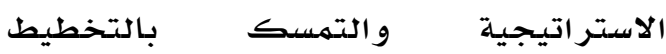

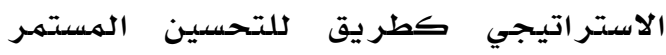

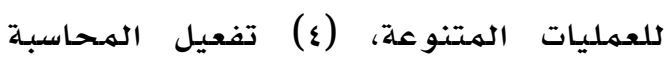

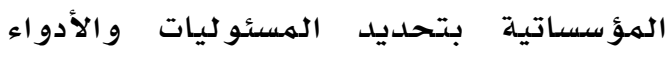
وصناعي ومتحخذي القرارات لتحقيق أهداف

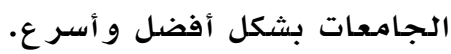

\section{مجالات تقييم الأداء في الجامعات والكليات}

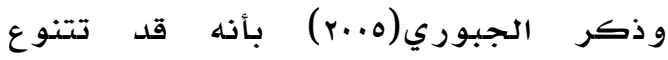
مجالات تقييم الجامعات و والكليات فتشهمل:

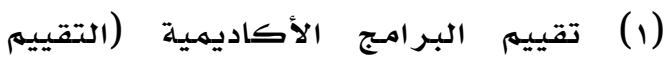
الذاتي أو التقييم الخخارجي)، (Y) (ب) التقييم

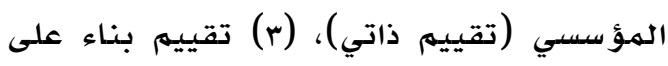

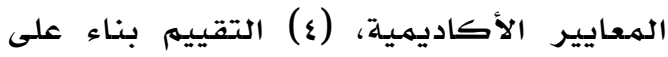

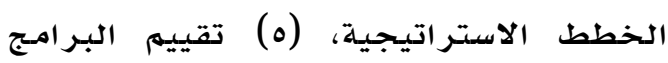




\section{بعد المستفيلين}

يهتم هذا البعد بتحقيق رضدا المستفيدين من

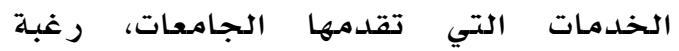

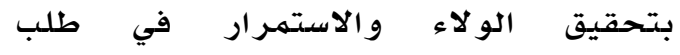

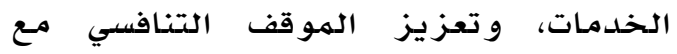

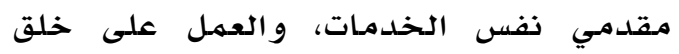
و سائل الجذب إيجاد طالبي الخدمات بشكل مستهمر مilsey, Perry \& Montgomery, 2013)

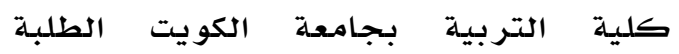

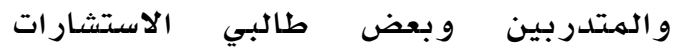

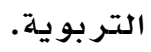

\section{بعد العمليات الداخلية}

يهتم هذا البعد بالقدرات والبهارات التي

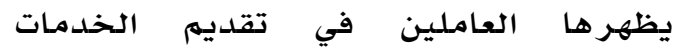

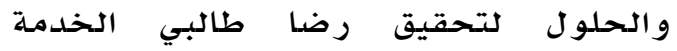
و تعزيز القدرات التنافسية للجامعة من خلال التركيز على العمليات و النماذج الإدارية

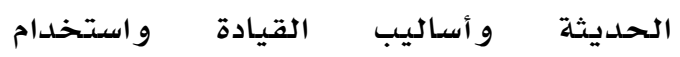

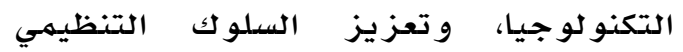
(Aljardali, Mazen \& Thierry, الايجابي الئولويال

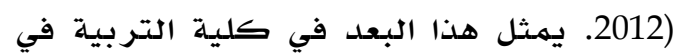
استثمـار النهماذج الإدارية في تطوير الخدمات

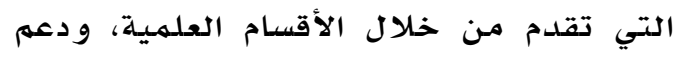
عمليات اتخاذ القرارات وحل المشكلات بشكل

$$
\text { علمي و عملي. }
$$

بعد التعلم والنمو

يهتم هذا البعد بعمليات التعلم والتعليم

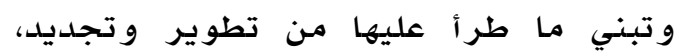

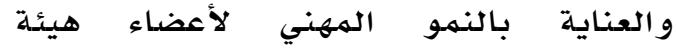

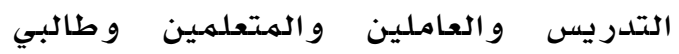

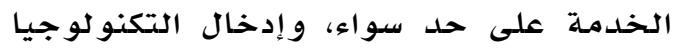
كوسيلة لإدارة المعرفة واستثمارها، و تبني

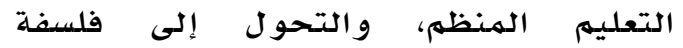

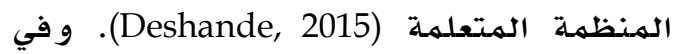
حالة كلية التربية بجامعة الكويت هناك رغبة لتطوير عمليات التعلهم والتعليم على به

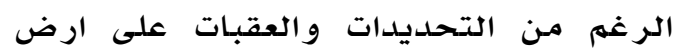

اهتمت بهوضوعات استخدام بطاقة الأداء المتوازن في الجامعات قليلة إلى حد ما، وان اندان

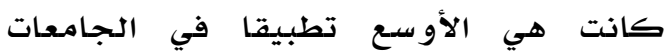

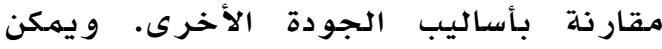

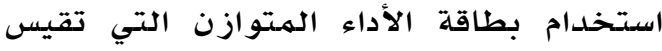
أنواع أخرى مـن الأداء بالإضدافة لـلأداء الماءلي كحلقة وصل بين التخطـيط الاسـتراتيجي اتئي

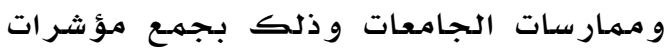

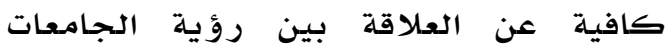
والأداء على أرض الواقع، ومساعدة مؤسسات

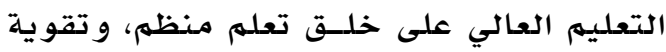
العلاقة بين الههام والبرامـج مـن جانب وبين الأداء و الأهداف من جانب أخر. و وأيضا يمكن الهن واتهن القول إنه تكمن فلسفة بطاقة الأداء المتوازن في خلق فرصة أفضل أمام الجامعات في تحويل رؤيتها و اإستر اتيجيتها إلى مقاييس موضوعية وو اقعية يسيرة التطبيق والتحليل

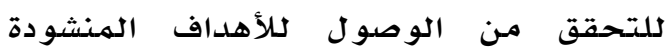
.(Luppicini, 2012)

\section{أبعاد بطاقة الأداء المتوازن}

تتمثل مـجالات بطاقة الأداء المتوازن بأربعة أبعاد تعمل معا للوصول إلى تحقيق التوازن بين الرؤية والاستر اتيجية من جانب والمال

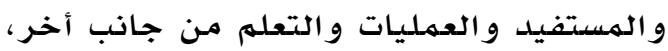
و التي تمثل مقاييس تعمل في تناغهم و تعاضد (Aljardali, Mazen \& Thierry, ودعم متبـادل وتهي (2012، ويمكن تقسىم تلك المقاييس إلى أربعة أبعاد هي كالآتي:

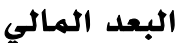

يركز هذا البعد على العمليات المالية

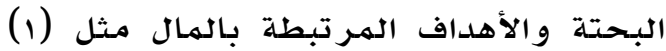

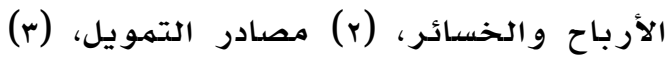

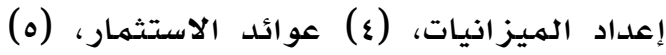

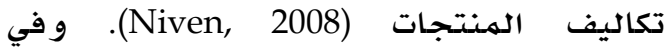
الجامعات الحكومية مثل الحالة في كلية الهية التربية في جامعة الكويت قد تختلف بعض العمليات في هذا البعد و لكن يبقى الاهتمام بالجانب المالي موجودا مؤثرا و يمكن ربطه ونهي

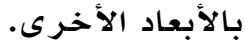




\section{عينة الدراسة}

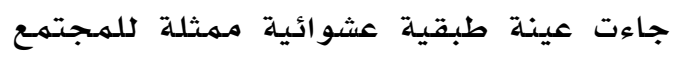

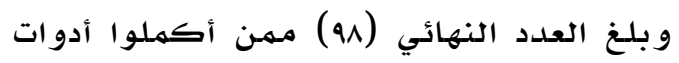

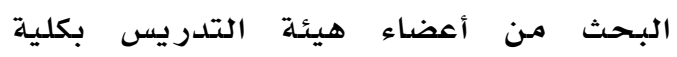
التربية جامعة الكويت.

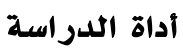

للإجابة على تساؤلات الدراسة الحالية تم تصميم استبيان لاستطلاع رأي عينة الدراسة

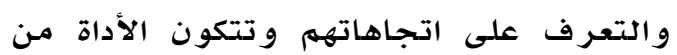

قسمين رئيسيين:

\section{القسم الأول: بيانات ديموغر افية}

وهي لغرض وصفي وتتضمن بنودا عن

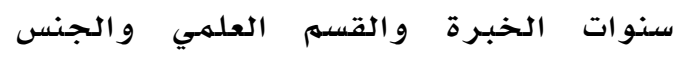
و الدرجة العلمية

القسم الثاني: ويتضمن ه محاور رئيسية

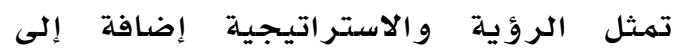
الأبعاد الأربعة لبطاقة الأداء المتوازئ والإني هي:

$$
\begin{aligned}
& \text { ا. الرؤية واستر اتيجيات العمل. } \\
& \text { r. مجال الإدارة المالية. } \\
& \text { r. رضا المستفيدين. } \\
& \text { ع. العمليات الداخلية. } \\
& \text { ه. التعلم و النهو. }
\end{aligned}
$$

واعتمد في تصميم الاستبيانة على مراجعة

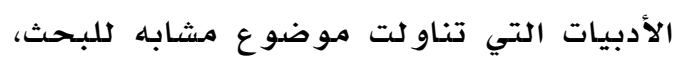

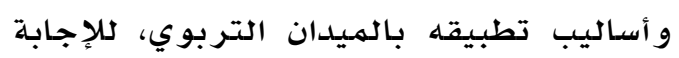
على تساؤلات الدراسة ويته استخداء

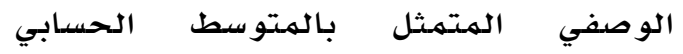

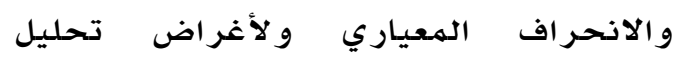

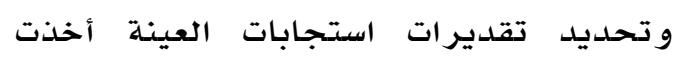
الأداة صورة مقياس ليكرت الخماسي لقياس

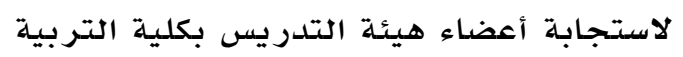

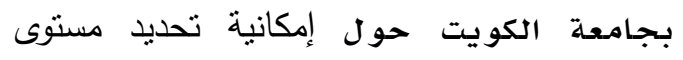
الأداء في كلية التربية بجامعة الكويت باستخدام بطاقة الأداء المتوازن بالشكل التالي (ه= (= كبير

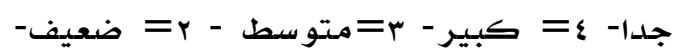
=1ضعيف جدا). وكان معيار الحكم على لى
الواقع مثل المبنى،وقلة عدد أعضاء هيئة

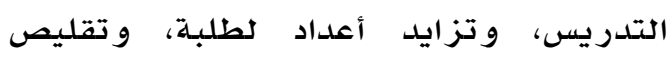

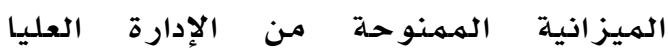

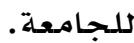

\section{الفائدة من بطاقة الأداء المتوازن}

Karathanos and لقد حدد كل من

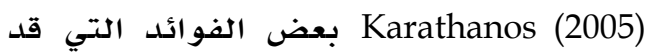
تتحقق عند تطبيق أبعاد بطاقة الأداء

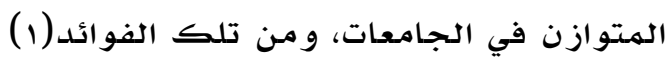

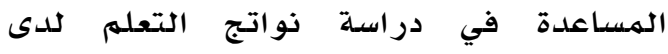

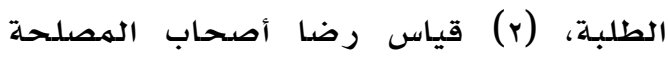

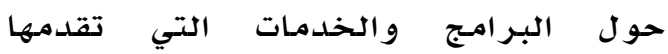
مؤسسات التعليم العالي، (r) ضبط التبل العمليات

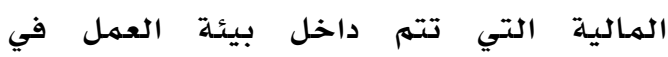
مؤسسات التعليم العالي من من الإرادات

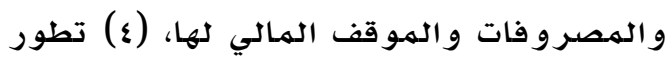

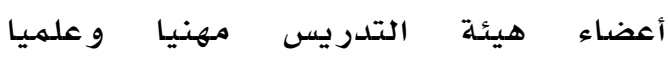

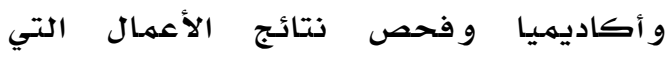

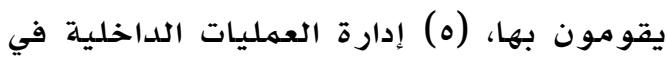

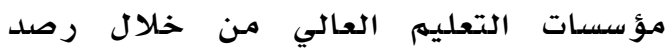
مؤشرات الأداء بشكل دقيق ومستمهر، و و(ج)

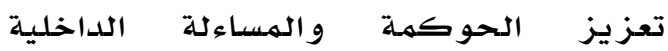
والخارجية في مؤسسات التعليم العالي.

\section{الطريقة والإجر اءات}

\section{منهجية الدراسة}

تم استخدام المنهج الوصفي والذي يتناسب

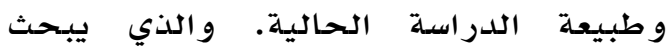
العلاقات بين متغيرات الدراسة دون محاولة الدرالة الدئة

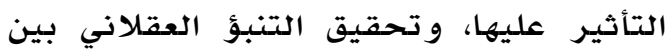
متغير ات الدر اسـة (مر اد و هادي، r. r. r ).

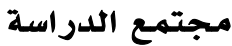

جميع أعضاء هيئة التدريس في كلية التربية بجامعة الكويت، والذين يشغلون الكئن

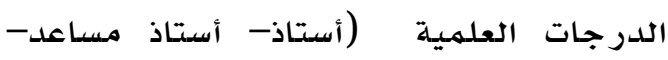

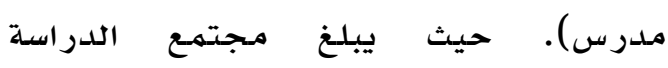

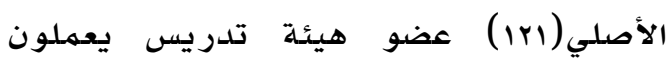
حتى اليوم في كلية التربية. 
وهذا يعني مستوى الأداء ضعيف من خلاءل

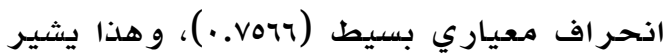

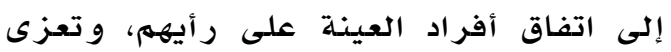
هذه النتيجة لحداثة بر نامـج تطبيق معايير الجودة في كلية التربية، إضافة إلى الإدارة

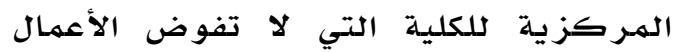
الإجرائية لأعضاء هيئة التدريس في الأقسام

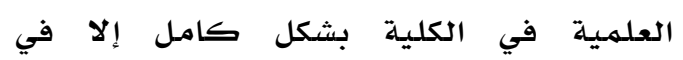

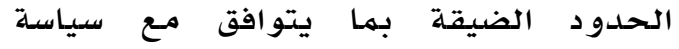

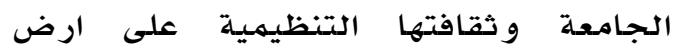

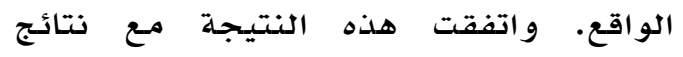

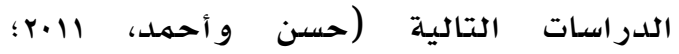

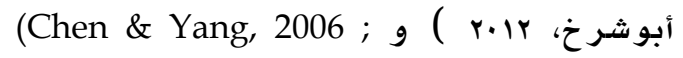
Umashaankar \& Dutta, 2007)

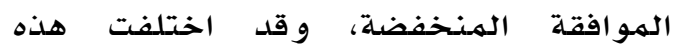

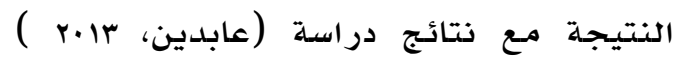
التي أشارت ارتفاع درجة الهو افقة.

و للإجابة على السؤال الثاني و الذي ينص

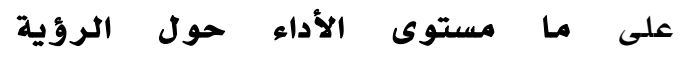
و استراتيجيات العمل في كلية التربية من فئ وجهة نظر أعضاء هيئة التدريسء تم التمئئ

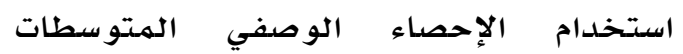

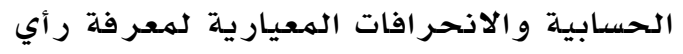
أعضاء هيئة التدريس على مستوى الأداء

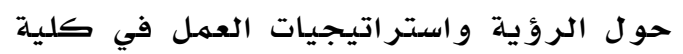
التربية، يلاحظ أن المتتوسط الحسابي الذي

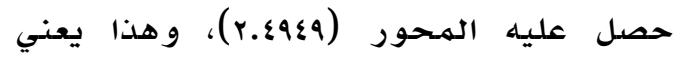
مستوى الأداء متوسط الهول الرؤية

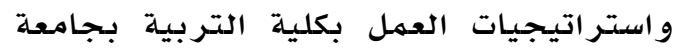

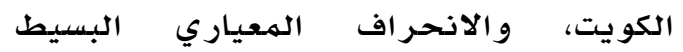

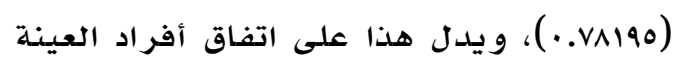

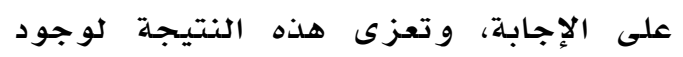

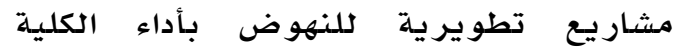

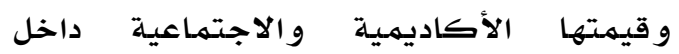
وخارج الجامعة، إضافة إلى وجود رونية رغبة لدى

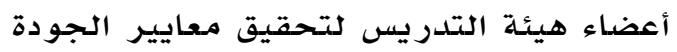

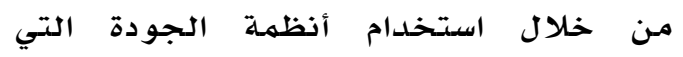
تتناسب وطبيعة الكلية، وتتفق هذه النتيجة

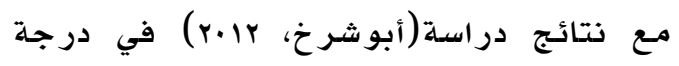
الموافقة المتوسطة.
الاستجابة من خلال القيم التالية: (من اب.؟

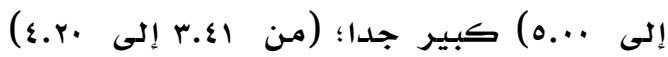

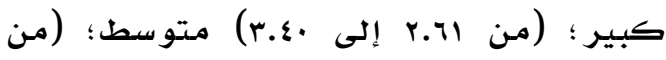

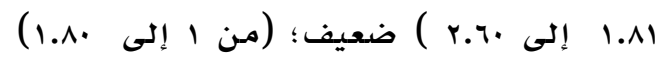

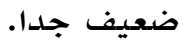

صدق الأداة وثباتها

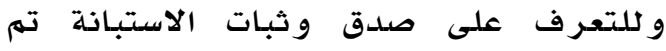

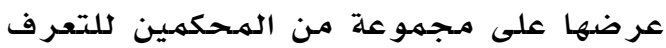

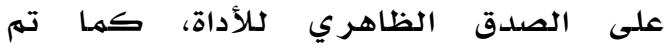

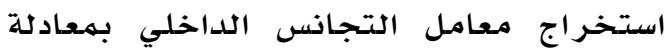
الفا كرونباخ للحصول على درجة ثبات محاور المقياس الخمسلة وبلغ معامل الثبات

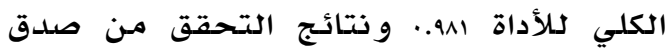
الاستبيان وثباته تظهر صلاحيته و وجودة

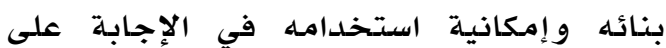

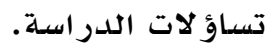
الأساليب الإحصائية

تم استخدام برنامج SPSS في تفريغ وتحليل بيانات المقياس، واستخدم الأدوات التالية (الهتوسط والانحراف الهعياري، النسبة الهبية الهئوية والتكرارات، تحليل التباين الأحادي One Way ANOVA الانحدار الهتعدد Multiple Regression Path معامل الارتباط الجزئي، تحليل الهسئعلددار .(Analysis

\section{النتائج والمناقشة}

الإجابة على السؤال الأول

لإِجابة على تساؤل الدراسة الأول و الذي

ينص على: ما مستوى الأداء في كليه كلية التربية بجامعة الكويت باستخدام بطاقة الأداء المتوازن من وجهة نظر أعضاء هيئة التدريسء، تم استخدام الإحصاء الوصفي

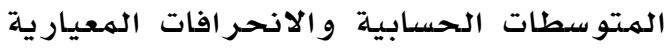

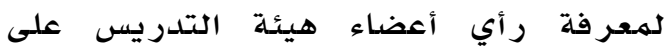
مستوى الأداء في كلية التربية باستخدام

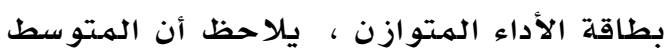

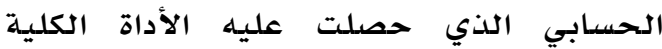

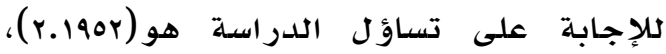


نظرا لحداثة برنامج تحقيق معايير الجودة

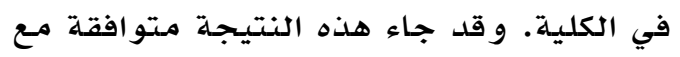

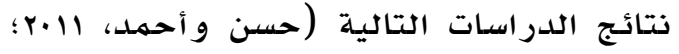

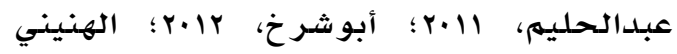

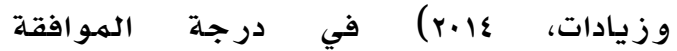
المنخفضة.

و للإجابة عن السؤال الخامس والذي ينص على ما إمكانية تقييم مستوى الأداء حول

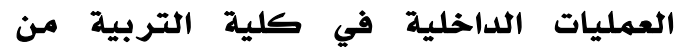
وجهة نظر أعضاء هيئة التدريسء، تم

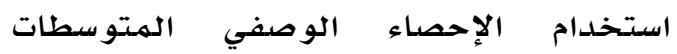

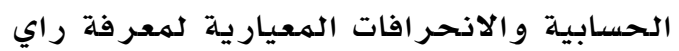
أعضاء هيئة التدريس في مستوى الأداء حول

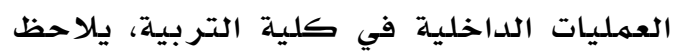
أن المتوسط الحسابي الذي حصل عليه

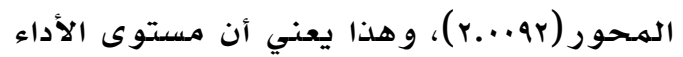

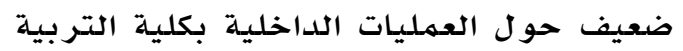
بجامعة الكويت، والانحر اف المعياري البسيط

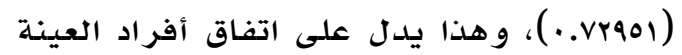
على الإجابة، تعزى هذه النتيجة إلى الروتين

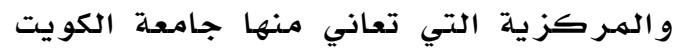
في إدارة الأعمال و والعلاقات مـع الكليات المختلفة التابعة لها، وكون الداره الكلية في بداية

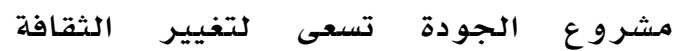
التنظيمية في بيئة العمل الداخلية. واتفقت

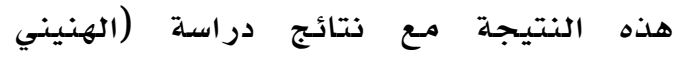

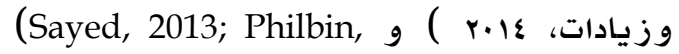
(2011 في درجة الموافوانقة المنخفضدة. وللإجابة عن السؤال السادس والذي ينص على ما إمكانية تقييم مستوى الأداء حول

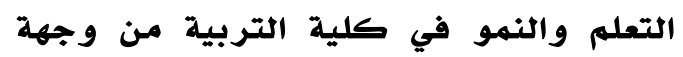
نظر أعضاء هيئة التدريسع تهم استخدام

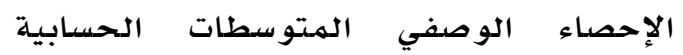
و الانحر افات المعيارية لمعرفة رأي أعضاء هيئة التدريس عن مستوى الأداء حول التعلهم والنهمو، يـلاحظ أن المتوسط الحسابي الذئي

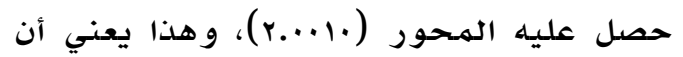
مستوى الأداء ضعحيف حول التعلم و النمو بكلية التربية بجامعة الكويت، والانحر اف افول

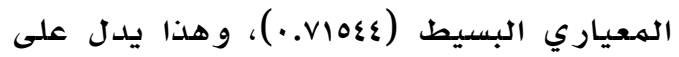

و للإجابة عن السؤال الثالث والذي ينص على ما إمكانية تحديد مستوى الأداء حول الإدارة المالية في كلية التربية من وجهة نظر أعضاء هيئة التدريسء تم استخدام الإحصداء

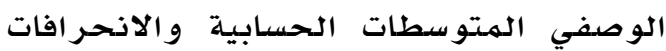
المعيارية لمعرفة رأي أعضداء هيئة التدريس التواله على مستوى الأداء حول الإدارة الهالية في لهيل كلية التربية، يـلاحظ أن الهتوسط الحسابي

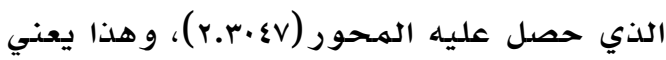
مستوى الأداء ضعيف حول الإدارة المالية

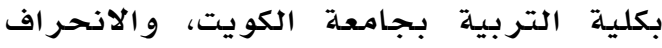

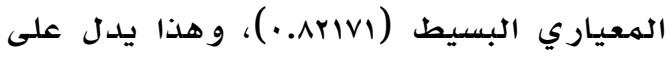
اتفاق أفراد العينة على الإجابة، و تعزى هلى هله

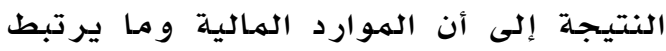

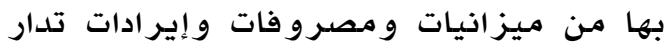
بشكل مـركزي على مستوى جامعة الكويت

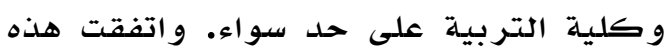

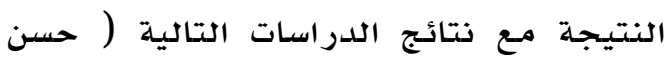
\&

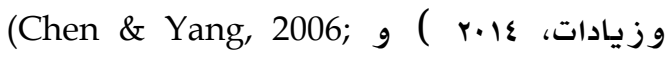
Umashaankar \& Dutta, 2007)

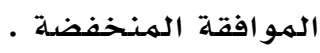

وللإجابة عن السؤال الرابع والذي ينص على مإد

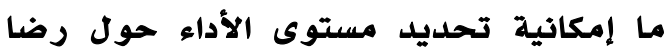
المستفيدين في كلية التربية من وجهة نظر أعضاء هيئة التدريسء تم استخدام

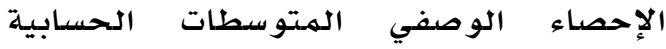

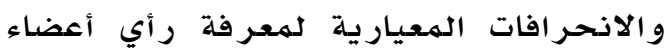

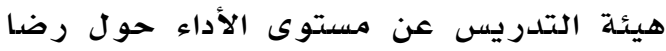

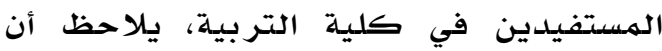

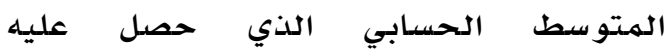
المحور (r.10VA)، وهذا يعني أن مستوى الأداء ضعيف حول رضا المستفيدين بكلية التربية وهورية بجامعة الكويت، والانحر اف المعياري البسيط

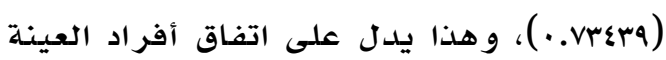

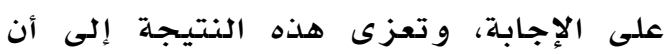
تطوير أساليب التعامل مـع المستفيدين يتمر من خلال مكاتب متخصصة بعيدة عن أعضاء هيئة التدريس، إضافة إلى الحاجة لر لرعاية المستفيدين من خلال المكاتب المتتخصصة إلى المصل 
يتضح من جدول ا انه لا توجد فروق ذات آمات

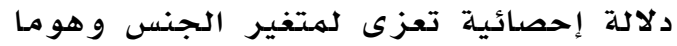

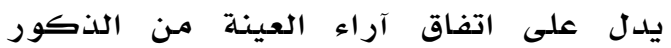

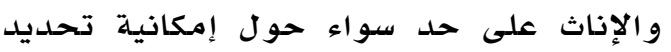
مستوى الأداء بكلية التربية باستخدام بطاقة

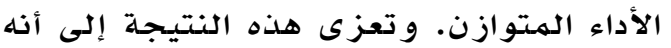
لا يوجد تمييز بين أعضاء هيئة التدريس من حيث الجنس فالجميع متساوون في الحقوق

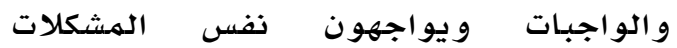
والتحديات داخل كلية التربية. يتضح من جدول r انه توجد فروق ذات دلادلة إحصائية تعزى لهتغير الدرجية الدو العلهية لصالح درجة أستاذ مـع جميع محاور الديله الدراسلة حول إمكانية تحديد مستوى الأداء بكليـة التربية باستخدام بطاقة الأداء المتهوازن. و تعزى هذه النتيجة لتمتع أعضاء هيئة التدريس مـ الأساتذة بخبرة وتاريخ طويل

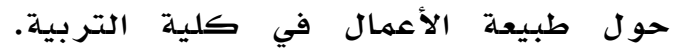

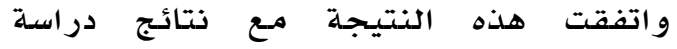

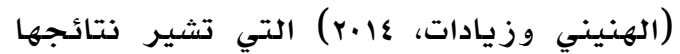
إلى وجود فروق لصالح الأساتذة، واختلفت هذه النتيجة مـع دراسة (Sayed, 2013) و التي والي لم يظهر فيها أي فروق._اما بالنسبة لمتغير القسهم العلهي، فقد تم استخدام تحليل التباين الأحادي وكما هو موضح في جدول r. ويتضسح من جدول r انه انلا توجد فروق

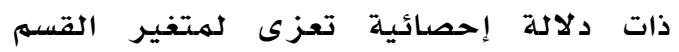

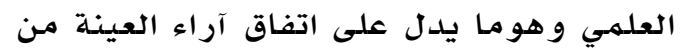

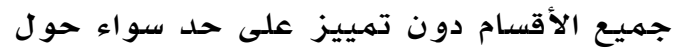
إمكانية تحديد مستوى الأداء بكلية التربية باستخدام بطاقة الأداء المتوازن. والعزى هذ هذه

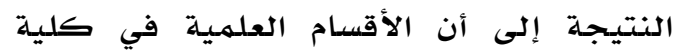

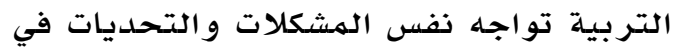

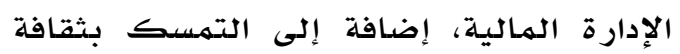

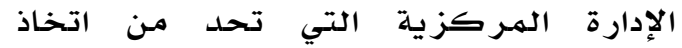

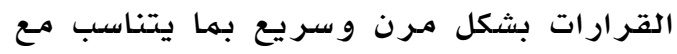

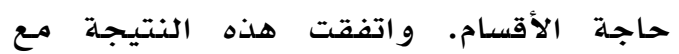

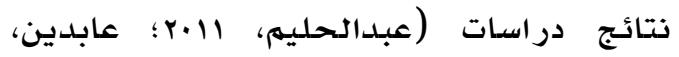

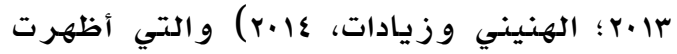
نتائجها فروقا لصالح الأقسدام العلمية.
اتفاق أفراد العينة على الإجابة، تعزى هذه النتيجة إلى أن عمليات التعلم والتعليم في كلية التربية لازالت تأخذ الطابع التقليدي التيلي

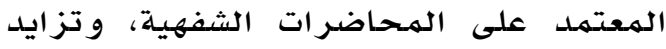
أعداد الطلبة المقبولين في الكلية خلادل

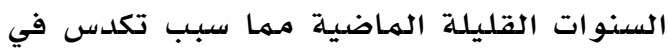
القاعات الدراسية وعدم قدرة أعضاء هيئة

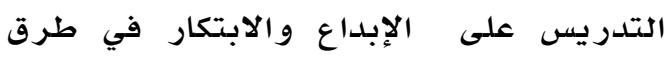

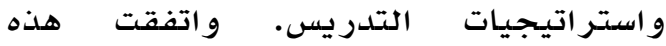

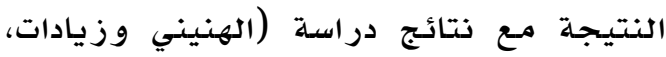

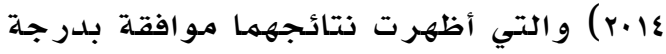
منخفضة، واختلفت هذه النتيجة مـع دراسة (Valderrama, Cornejo \& Bordoy, 2013) و التي كانت بهما الموافقة بلدرجة عالية.

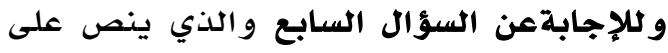
هل هناك فروق ذات دلالة إحصائية حول إمكانية تقييم مستوى الأداء في كلية التربية بجامعة الكويت باستخدام بطاقة الأداء المتوازن من وجهة نظر أعضاء هيئة

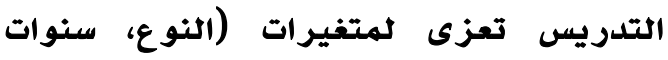

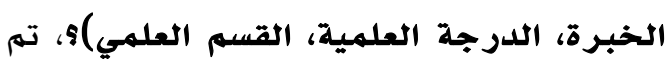
استخدام اختبار ت للعينات المستقلة وتحليل

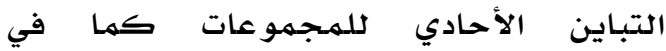

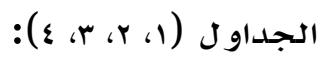

$$
\text { جدول الائ } 1
$$

\begin{tabular}{|c|c|c|c|c|}
\hline \multicolumn{5}{|c|}{ الجنس } \\
\hline قيمة & المتوسط & التكرار & الجنس & المحور \\
\hline \multicolumn{5}{|l|}{ ت } \\
\hline \multirow[t]{5}{*}{$1.1 \mathrm{ro}^{-}$} & T.OTYO & Tr & ذكر & الروية \\
\hline & T.TYNo & ד & أنثى & واستراتيجيات \\
\hline & & & & العمل \\
\hline & ع זس.. & Tr & ذكر & مجال الإدارة \\
\hline & $r . T \leq 1 T$ & דיז & أنثى & المالية \\
\hline \multirow[t]{2}{*}{$. r \leqslant 0$} & Y.IVVE & Tr & ذكر & رضا \\
\hline & Y.IY & דו & أنثى & المستفيدين \\
\hline \multirow[t]{2}{*}{.71} & $r . . r \leq 0$ & Tr & ذكر & العمليات \\
\hline & $1.90 \ldots$ & די & أنثى & الداخلية \\
\hline \multirow[t]{2}{*}{.704} & r...rVI & Tr & ذكر & التعلم والنمو \\
\hline & $1.94 \wedge 9$ & די & أنتى & \\
\hline
\end{tabular}

متوسطات الذكور والإناث وقيم ت للاختبار دلالة متغير 


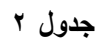

نتائج تحليل التباين الأحادي ANOVA لأثر متغير الدرجة العلمية

\begin{tabular}{|c|c|c|c|c|c|}
\hline قيمة ف* & متوسط المربعات & درجات الحرية & مجموع المربعات & مصدر التباين & المحور \\
\hline \multirow[t]{3}{*}{ V.TVY } & r.TV9 & $\varepsilon$ & $|\leq . \vee 7|$ & بين المجموعات & الروية \\
\hline & $\cdot . \leqslant \wedge$. & 94 & $\sum \varepsilon .09 \varepsilon$ & داخل المجموعات & واستراتيجيات \\
\hline & & $9 \vee$ & 09.51. & المجموع & العمل ل \\
\hline \multirow[t]{3}{*}{ 纟.qTr } & Y.人тT & $\varepsilon$ & $11 . \leqslant 7 \%$ & بين المجموعات & مجال الإدارة المالية \\
\hline &. .011 & 9 & TE...rT & داخل المجموعات & \\
\hline & & १४ & $70 . \leqslant 90$ & المجموع & \\
\hline \multirow[t]{3}{*}{ V.V०q } & T.rVT & $\varepsilon$ & $15 . .9$. & بين المجموعات & رضا المستقيدين \\
\hline & $\cdot . \leqslant r r$ & 9 & rq.rTo & داخل المجموعات & \\
\hline & & १V & Or.r. & المجموع & \\
\hline \multirow[t]{3}{*}{ N.r. 9} & r.raA & $\varepsilon$ & 15.091 & بين المجموعات & العمليات الداخلية \\
\hline & $\cdot . \varepsilon \cdot 9$ & 9 & rA..rT & داخل المجموعات & \\
\hline & & $9 \vee$ & $01.7 K Y$ & المجموع & \\
\hline \multirow[t]{3}{*}{7.917} & $Y . \wedge \leq T$ & $\varepsilon$ & 11.r人ז & بين المجموعات & التعلم والنمو \\
\hline & $\cdot . \leqslant 11$ & 9 Tr & rA.tTV & داخل المجموعات & \\
\hline & & १४ & $\leq 9.70$ & المجموع & \\
\hline
\end{tabular}

جدولr

نتائج تحليل التباين الأحادي One Way ANOVA لمتغير القسم العلمي (ء مجموعات)

\begin{tabular}{|c|c|c|c|c|c|}
\hline قيمة ف & متوسط المربعات & درجات الحرية & مجموع المربعات & مصدر التباين & المحور \\
\hline \multirow[t]{3}{*}{$\because 1 \times 9$} & $.11 r$ & r & VTr. & بين المجموعات & الروئية \\
\hline & . .TYV & $9 \varepsilon$ & $0 \wedge .9 V T$ & الدجموعات & \\
\hline & & $9 \vee$ & 09.51. & المجموع & ושה \\
\hline \multirow[t]{3}{*}{.$r M}$. & .109 & r & $\therefore \leqslant \vee \uparrow$ & بين المجموعات & \\
\hline & $.79 r$ & $9 \varepsilon$ & $70 . .19$ & داخل & مجال الإدارة \\
\hline & & $9 \vee$ & $70 . \leqslant 90$ & المجموع & \\
\hline \multirow[t]{3}{*}{$\because$ ros } & $. .1 \leqslant$. & $r$ & $. . \leqslant r \mid$ & بين المجموعات & \\
\hline & $.00 r$ & $9 \varepsilon$ & $01.19 \leq$ & داخل & رضا المستقيدين \\
\hline & & $9 \vee$ & Or.rio & المجموع & \\
\hline \multirow[t]{3}{*}{$\cdot T \cdot Y$} & DO THO & r & $.9 \vee \leqslant$ & بين المجموعات & \\
\hline & .049 & $9 \leq$ & $0.7 \leqslant 1$ & المجموعات & العمليات الداخلية \\
\hline & & $9 \vee$ & $01.74 r$ & المجموع & \\
\hline \multirow[t]{3}{*}{.719} & . & r & .971 & بين المجموعات & \\
\hline &. .011 & $9 \varepsilon$ & $\sum \wedge .7 \wedge 9$ & داخل & التعلم والنمو \\
\hline & & $9 \vee$ & $\leqslant 9.70$. & المجموع & \\
\hline
\end{tabular}


جدول

نتائج تحليل التباين الأحادي (ANOVA) لمتغير سنوات الخبرة (0 مجموعات)

\begin{tabular}{|c|c|c|c|c|c|}
\hline قيمة ف ق* & متوسط المربعات & درجات الحرية & مجموع المربعات & مصدر التباين & المحور \\
\hline \multirow[t]{3}{*}{ V.TVY } & r.7v9 & $\varepsilon$ & $1 \varepsilon . V 17$ & بين المجموعات & الرؤية \\
\hline & $\cdot . \Sigma \wedge$ & q & $\varepsilon \varepsilon .09 \varepsilon$ & داخل المجموعات & واستراتيجيات \\
\hline & & $9 \vee$ & oq.r. & المجموع & 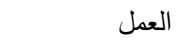 \\
\hline \multirow[t]{3}{*}{ E.qru } & ケ.人тฺ & $\varepsilon$ & $11 . \varepsilon T r$ & بين المجموعات & مجال الإدارة \\
\hline & .011 & 94 & אז... & داخل المجموعات & المالية \\
\hline & & $9 \vee$ & 70.590 & المجموع & \\
\hline \multirow[t]{3}{*}{ V.v०9 } & T.YVT & $\varepsilon$ & 15.9. & بين المجموعات & رضا \\
\hline & ..EYr & 94 & rq.rro & داخل المجموعات & المستفيدين \\
\hline & & $9 v$ & or.rio & المجموع & \\
\hline \multirow[t]{3}{*}{ A.r. 9} & r.rqA & $\varepsilon$ & 15.091 & بين المجموعات & العمليات الداخلية \\
\hline & $\cdot . \varepsilon \cdot q$ & 94 & 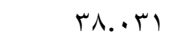 & داخل المجموعات & \\
\hline & & $9 \vee$ & $01.7 r T$ & المجموع & \\
\hline \multirow[t]{3}{*}{7.917} & $Y . \wedge \leq 7$ & $\varepsilon$ & M.r & بين المجموعات & التعلم والنمو \\
\hline &.$\leqslant 11$ & q4 & r人.YTV & داخل المجموعات & \\
\hline & & qV & $\leqslant 9.70$. & المجموع & \\
\hline
\end{tabular}

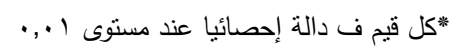

الداخلية والتعلم والنمو) على تحقيق الرؤية

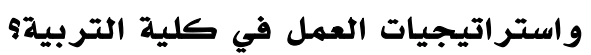

الهدف من السؤال هو التعرف على الأثر

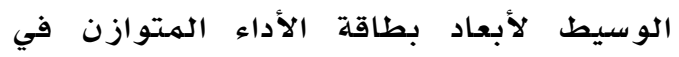

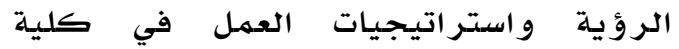

التربية بجامعة الكويت على الإدارة المالية

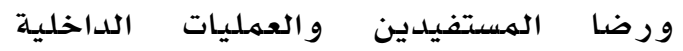

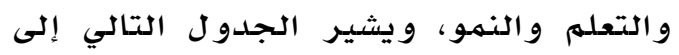

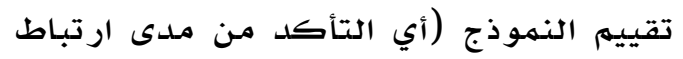

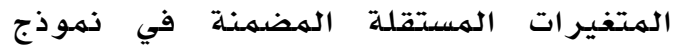
بطاقة الأداء المتوازن بالمتغير التابع الدئي الدئي

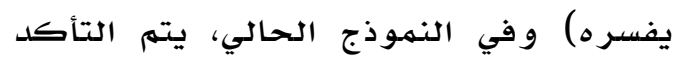

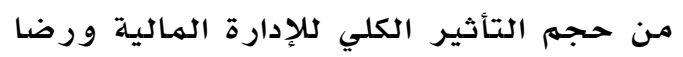

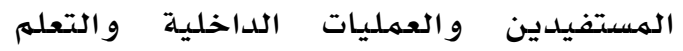
والنهو على استراتيجيات العمل في كلية التر بية. - النو

وقد بين تحليل التباين أن النموذج الحالي

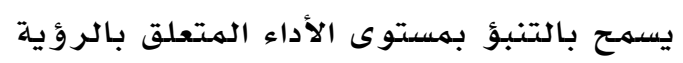
واستراتيجيات العمل في كلية التربية بناء على مستوى الأداء باستخدام بطاقية الأداء

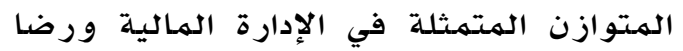

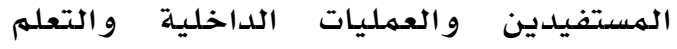

يتضح من جدول ؛ إنه توجد فروق ذات دلالة

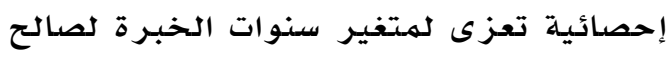

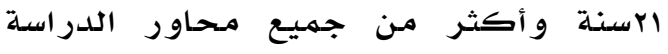
حول إمكانية تحديد مستوى الأداء بكلية التربية باستخدام بطاقة الأداء المتوازن. و تعزى هذه النتيجة أن القدماء من أعضاء

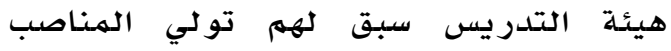

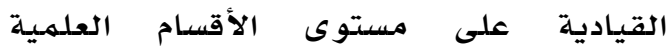

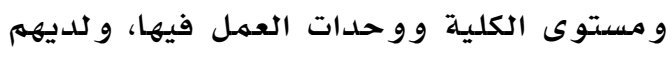

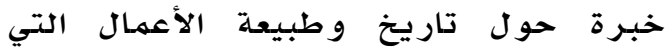

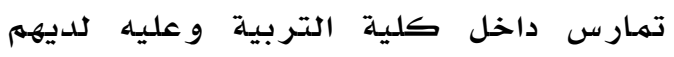

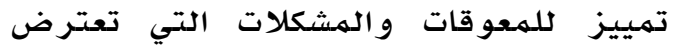
تحقيق معايير الجودة وتبني أنظمة الجودة

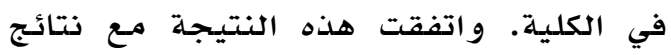

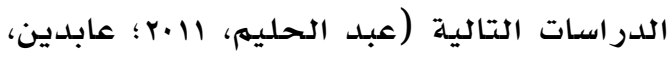

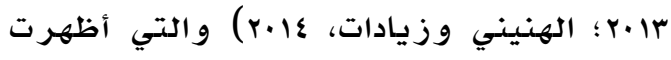
نتائجها فروقا مهممة لصايح أصداب الخبرة

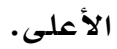
وللإجابة عن السؤال الثامن و الذي ينص على الذي

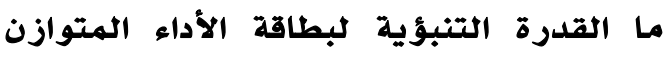
(الإدارة المالية ورضا المستفيدين والعمليات 


$$
\begin{aligned}
& \text { وكذلك تقدير إسهام كل منها على حدة، } \\
& \text { ونتائج الهعامـلات الخاصـة بالنهموذج. } \\
& \text { جدول ه } \\
& \text { نتائج الانحدار المتعدد للمحاور الدالة }
\end{aligned}
$$

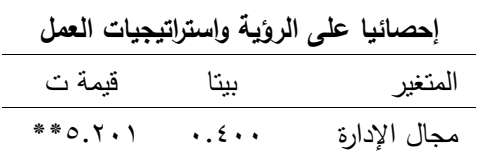

$$
\begin{aligned}
& \text { المالية } \\
& \text { رضا المستقيدين } \\
& \text { العمليات }
\end{aligned}
$$

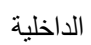

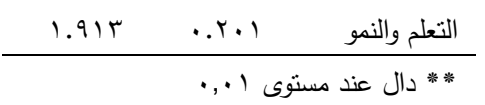

يتبين من جدول

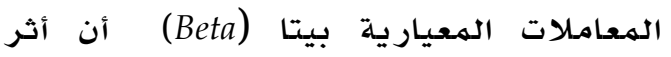

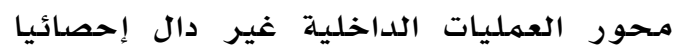

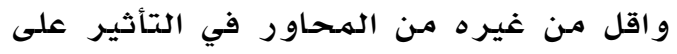

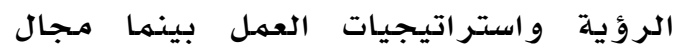

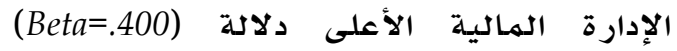
ويسهم أكثر من غيره في تفسير التباين الهماره

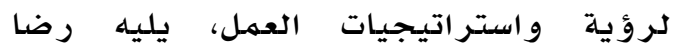

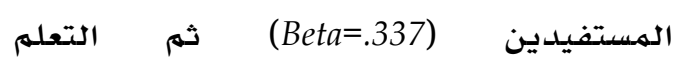
و النهمو (Beta=.201)، و يبيين الشكل (1) (1) نتائج تحليل الهسار للنموذذج الحالي.
والنمو، فقد كانت قيمة مربع معامل الارتباط الكلي تساوي (rیr.)، ووهي دالة عنداند

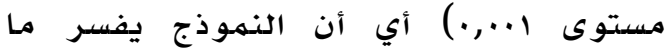
نسبته (\%.r\%) من حجم التباين في الرؤية

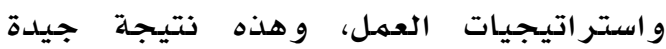

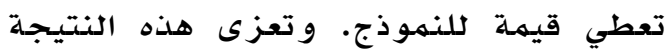
إلى رغبة أعضاء هيئة التدريس في في كلية فية فئ التربية في تطوير وتغيير الأداء من خلاءل استخدام أنظمهة الجودة التي تتناسب وطبئ وطبيعة الكلية مثل بطاقة الأداء المتوازن، إضـافة إلى إنى أن ما يمارس من عمليات تطويرية باتجاه

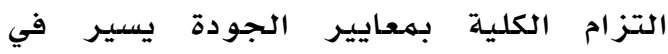
الاتجاه الصحيح نحو التطوير وتحسين

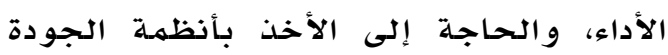

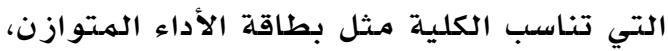

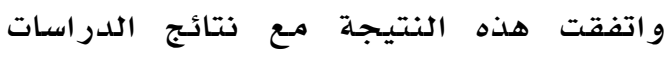

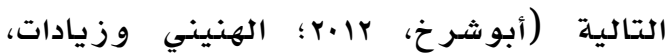
(Valderrama, Cornejo \& Bordoy, و (

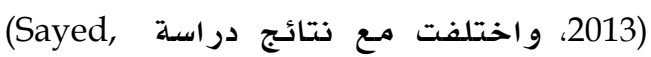

ويشير جدول ه إلى تقييم باقي بطاقة الأداء

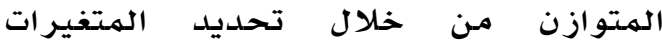
المستقلة المتضمنـة في النموذج وازئ والتي كان لها إسهام مهيز في التنبؤ بالهتغير التابع، الهودئ

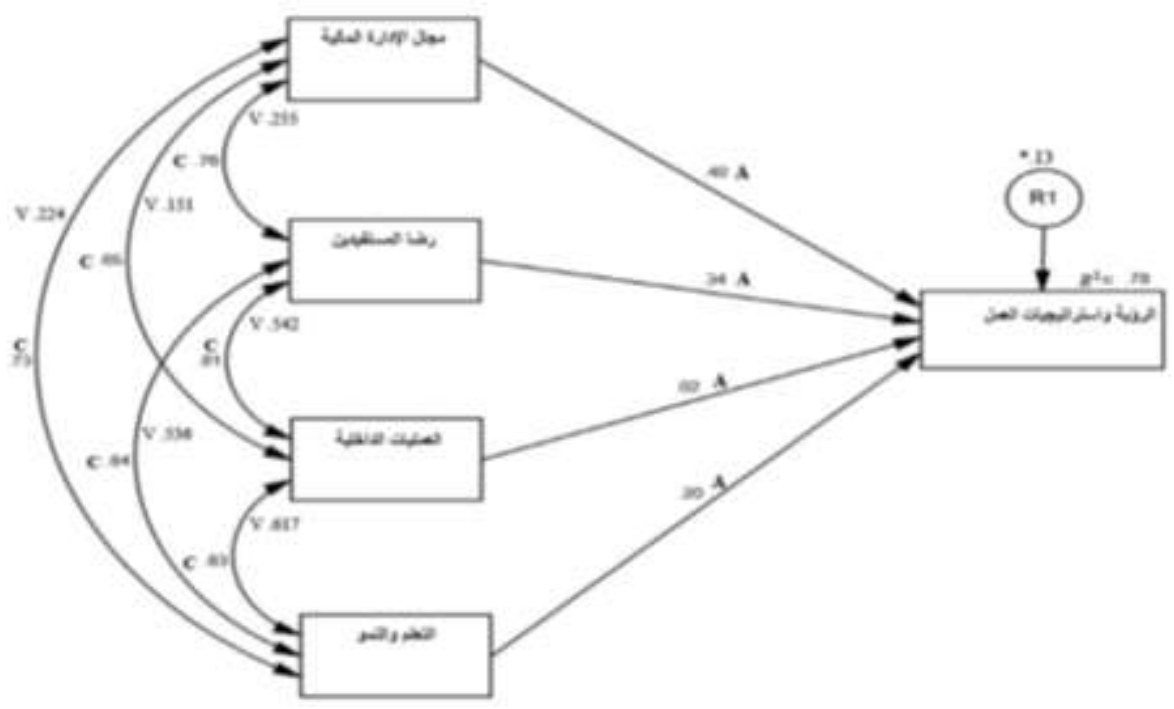

شكل ا : نتائج تحليل المسار للنموذج الحالي. 


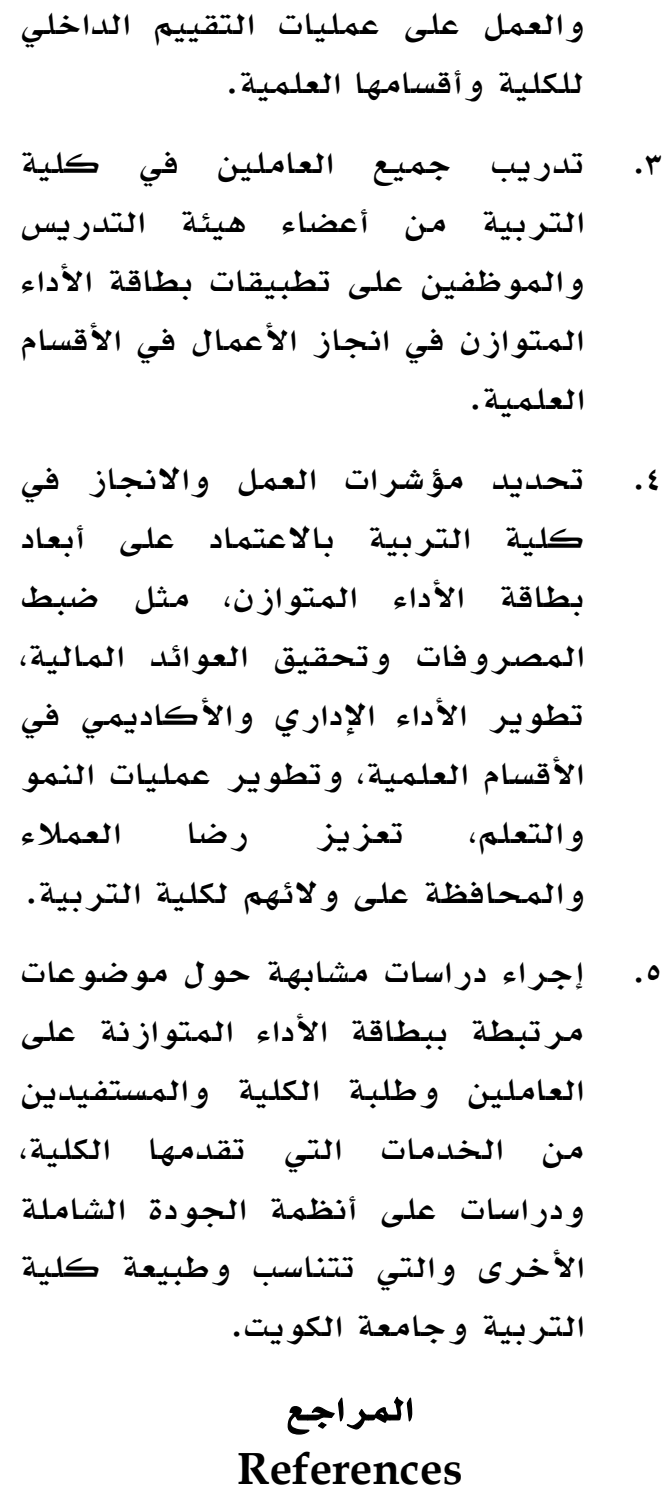

\section{References}

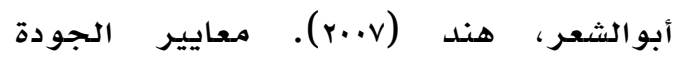

المعتمددة في مؤسسات التعليهم العالي في جامعة آل البيت في الأردن نموذجا، المؤتمر السادس لعمداء كليات الآداب في الجامعات العربية، طر ابلس، لبنان. أبوشرخ، جمال (r/r). مدى إمكانية تقويم

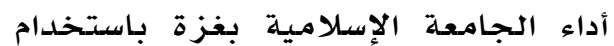
بطاقة الأداء المتوازن. رسالة ماجستير

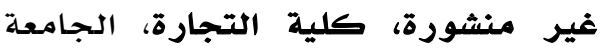
الإسـلامية بغزة، فلسطين.

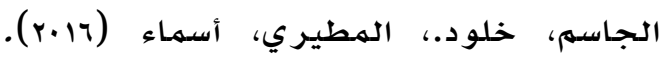
قياس أداء جامعة الكويت. مكتب نائب مدير الجامعة لتخطيط. جامعة الكويت.
Beta قيم A r معامل الارتباط C

Partial معامل الارتباط الجزئي V Correlation المتغير الكامن و بالنظر إلى معاملات الارتباط شبـه الجزئية، يمكننا معر فة مقدار إسهام كل متغير في

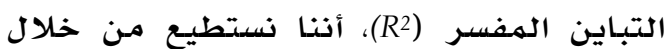
تربيع هذه القيمة معرفة مقدار التباين في

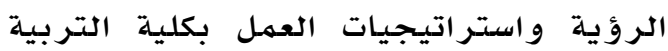
الذي يفسره هذا المتغير على حده (الأثر

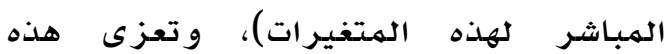
النتيجة إلى الحاجة إلى تغيير في العمليات الداخلية من خلال تغيير الثقافة التنظيمية من خلال تحول إلى تحقيق مبادئ الجودة

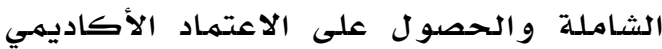

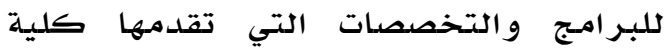

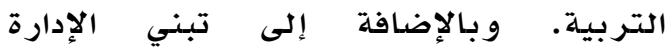

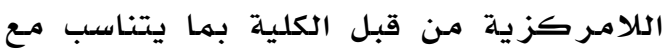

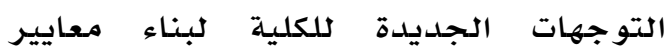

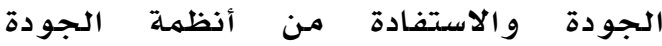
و النهاذج الإدارية و القيادية و التي تتناسب مـع

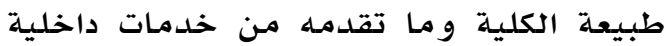

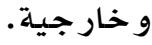

التو صيات و المقتر حات

ا. استخدام بطاقة الأداء المتوازن

و أبعادها في تطوير العمل في كلية

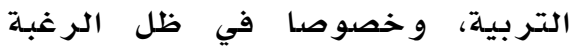

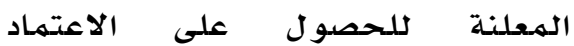
الأكاديمي من جهات خارجية محايدة

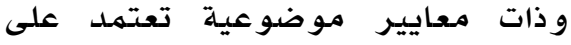
أنظمة الجودة مثل أبعاد بطاقة الأداء الهـتوازن كمؤشر ات لكلأداء الجيد.

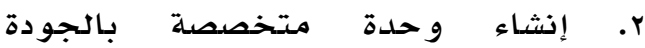
الشاملة و أنظمتها المختلفة مثل بطاقة الأداء المتوازن، للمساعدة على تحقيق رؤية واستر اتيجية كلية التربية، 


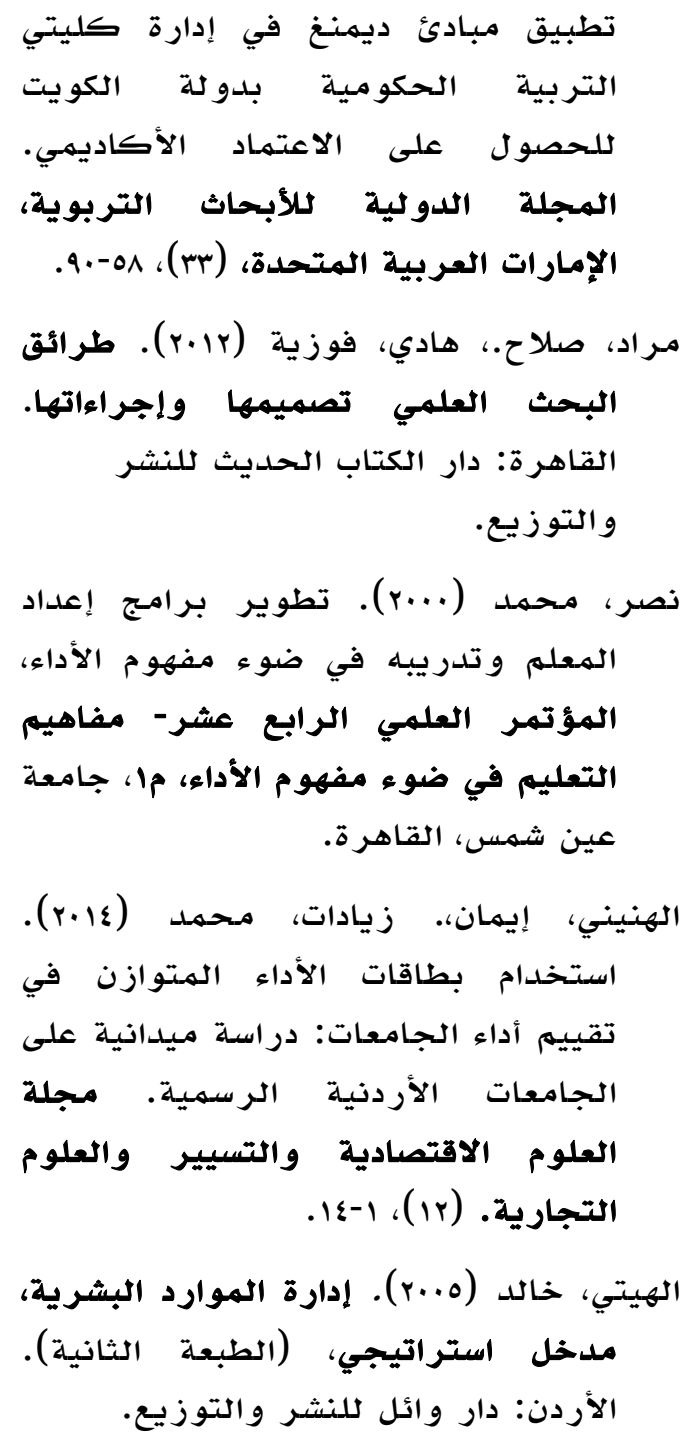

Alazmi, M. (2011). The extent of applying NCATE Academic Accreditation Standards in the Faculty of Education at Kuwait University. Delhi Business Review, 12 (1), 51-67.

Aljardali, H., Mazen, K., \& Thierry, L. (2012). The Implementation of the Balanced Scorecard in Lebanese Public Higher Education Institutions. Procedia, Social and Behavioral Science (62) 98-108.

Afriliana, N., Goel, F. (2014). Performance Measurement of Higher Education Information System Using IT Balanced Scorecard. Intelligent Information and Database Systems. Springer international publishing, 412-421.

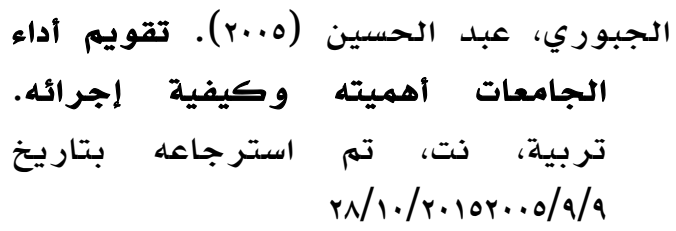
cialFiles.aspx?TypeId=7

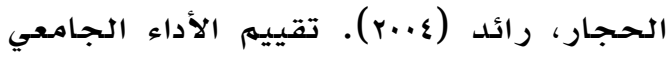

من وجهة نظر أعضاء الهيئة التدريسية

بجامعة الأقصى في ضوء مفهوم الجودة

الشاملة. مجلة جامعة الأقصى، سلسلة فيلة فئو الجودة

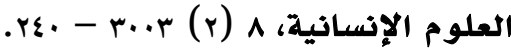

حسن، علاء، أحمد، ميسون (11) (ب). قياس أداء جامعة الموصل وتاعييمه باستخدام

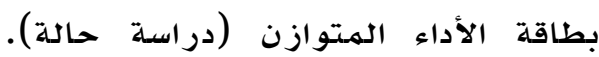

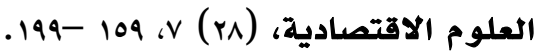

درة، عبدالباري (r.r.r). تكنولوجيا الأداء البشري في المنظمات. مصر: منشورات المنظمة العربية الإدارية.

الرازي، محمد (1994). مختار الصحاح. القاهرة: دار المنار.

عابدين، حسني (rاء.r). مدىى استخدام بطاقات الأداء المتوازن (BSC) لتقويم أداء كلية

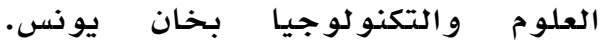
المؤتمر الأول للدور الكليات والجامعات

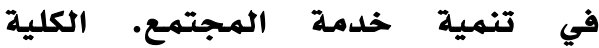
الجامعية للعلوم والتكنولوجيا، خان الفئية

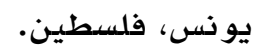

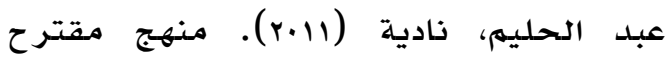
لتقييم أداء الجامعات وتحسين جودة الجادئ التعليم الجامعي. المؤتمر الدولي الأول الجداء

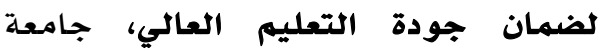

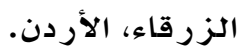

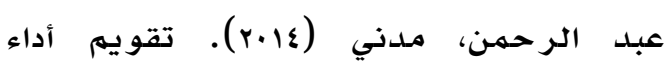
الجامعات وفقا لمنظور الأداء المتوازن. مجلة كلية الاقتصاد، جامعة أفريقيا

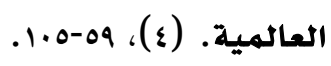

القحطاني، عبدالمحسن، العازني، مزنة، المحيلبي، عبدالعزيز (rا.ب). آليات 
Chen, S., Yang, C., Shiau, J. (2006).The Application of Balanced Scorecard in the Performance Evaluation of Higher Education. The TQM Magazine, 18 ( 2 ), $190-205$.

Deshande, B. (2015). Application of balanced score card in higher education with special emphasis in a business school. International Conference on Technology and Business Management. March 23-25, 2015, 201205.

Karathanos, D., Karathanos, P. (2005). Applying the balanced scorecard to education. Journal of Education for Business, 80 ( 4 ), 222-30.

Luppicini, R. (2012). Cases on technologies for educational leadership and administration in higher education. USA:IGI Global.

Hu, J. H. (2002). Study on the national university performance management system by a case school using balanced scorecard. Unpublished master's thesis, National SunYat-Sen University, Kaohsiiung, Taiwan, 2002.

Hladchenko, M. (2015). Balanced scorecard- a strategic management system of the higher education institution. International Journal of Educational Management, 29 ( 2 ),167176.

Philbin, S. (2011). Design and implementation of the balanced scorecard at a university institute. Measuring Business Excellence, 15 ( 3 ), $34-45$.

Sayed, N. (2013). Ratify, reject or revise balanced scorecard and universities. International Journal of Educational Management, 27 ( 3 ), 203- 220.

Steele, J. (2001). Transforming the balanced scorecard into your strategy execution system. Manage, 1 (1), 22 3.

Niven, P. (2008). Balanced scorecard: Stepby-step for government and nonprofit agencies ( $2^{\text {nd }}$ ed.). USA: Wiley.

Owlia M. S., Aspinwall, E. M. (1996).

Quality in higher education - a survey.
Total Quality Management, 7(2), 161-

171.

Roha, H., Wilsey, D., Perry, G. \& Montgomery, D. (2013). The institute way: simplify strategic planning and management with the balanced scorecard. USA: The Institute Press.

Umashankar, V., Dutta, K. (2007). Balanced scorecards in managing higher education institutions: An Indian perspective. International Journal of Educational Management, 21 (1), $54-67$.

Valderrama, T., Cornejo, V., Bordoy, D. (2013).Balanced scorecard and efficiency: Design and empirical validation of a strategic map in the university by means of DEA. American Journal of Operations Research, 3 (1), 3052.

psychologists used to study false memory and what are the implications of these choices. Consciousness and Cognition, 16(1), 2-17.

Schacter, D., \& Dodson, C. (2001). Misattribution, false recognition and the sins of memory. Philosophical Transactions of the Royal Society of London Series B: Biological Sciences, 356(1413), 1385-1393.

Sugrue, K., Strange, D., \& Hayne, H. (2009). False memories in the DRM paradigm: Age-related differences in lure activation and source monitoring. Experimental Psychology, 56 (5), 354-360.

Watson, J., Bunting, M., Poole, B., \& Conway, A. (2005). Individual differences in susceptibility to false memory in the Deese-RoedigerMcDermott paradigm. Journal of Experimental Psychology Learning Memory and Cognition, 31 (1), 76-85. 